\title{
Bidirectional Hebbian Plasticity at Hippocampal Mossy Fiber Synapses on CA3 Interneurons
}

\author{
Emilio J. Galván, ${ }^{1}$ Eduardo Calixto, ${ }^{2}$ and Germán Barrionuevo ${ }^{1}$ \\ ${ }^{1}$ Department of Neuroscience, University of Pittsburgh, Pittsburgh, Pennsylvania 15260, and 2División de Investigaciones en Neurociencias, Instituto \\ Nacional de Psiquiatría, 14370 Mexico D.F., Mexico
}

\begin{abstract}
Hippocampal area CA3 is critically involved in the formation of nonoverlapping neuronal subpopulations ("pattern separation") to store memory representations as distinct events. Efficient pattern separation relies on the strong and sparse excitatory input from the mossy fibers (MFs) to pyramidal cells and feedforward inhibitory interneurons. However, MF synapses on CA3 pyramidal cells undergo longterm potentiation (LTP), which, if unopposed, will degrade pattern separation because MF activation will now recruit additional CA3 pyramidal cells. Here, we demonstrate MF LTP in stratum lacunosum-moleculare (L-M) interneurons induced by the same stimulation protocol that induces MF LTP in pyramidal cells. This LTP was NMDA receptor (NMDAR) independent and occurred at MF $\mathrm{Ca}^{2+}$ impermeable AMPA receptor synapses. LTP was prevented by with voltage clamping the postsynaptic cell soma during high-frequency stimulation (HFS), intracellular injections of the $\mathrm{Ca}^{2+}$ chelator BAPTA $(20 \mathrm{mM})$, or bath applications of the L-type $\mathrm{Ca}^{2+}$ channel blocker nimodipine $(10 \mu \mathrm{M})$. We propose that MF LTP in L-M interneurons preserves the sparsity of pyramidal cell activation, thus allowing CA3 to maintain its role in pattern separation. In the presence of the mGluR1 $\alpha$ antagonist LY367385 $[(S)-(+)$-a-amino-4-carboxy-2methylbenzeneacetic acid] $(100 \mu \mathrm{M})$, the same HFS that induces MF LTP in naive slices triggered NMDAR-independent MF LTD. This LTD, like LTP, required activation of the L-type $\mathrm{Ca}^{2+}$ channel and also was induced after blockade of $\mathrm{IP}_{3}$ receptors with heparin $(4 \mathrm{mg} / \mathrm{ml})$ or the selective depletion of receptor-gated $\mathrm{Ca}^{2+}$ stores with ryanodine $(10$ or $100 \mu \mathrm{M})$. We conclude that L-M interneurons are endowed with $\mathrm{Ca}^{2+}$ signaling cascades suitable for controlling the polarity of MF long-term plasticity induced by joint presynaptic and postsynaptic activities.
\end{abstract}

Key words: mossy fiber; LTP; LTD; calcium-impermeable AMPARs; CA3 interneurons; feedforward inhibition

\section{Introduction}

The circuitry of area CA3 is believed to transform neocortical inputs in a way that overlap between different activity patterns is minimized ("pattern separation") (McNaughton and Morris, 1987; Treves and Rolls, 1992; O'Reilly and McClelland, 1994; Leutgeb and Leutgeb, 2007). This pattern separation facilitates storage of distinct episodic memories and reduces recall errors. Computational models of hippocampal connectivity (Treves and Rolls, 1992) have shown that pattern separation requires parallel activation of two excitatory afferent inputs to area CA3: the perforant path (PP), the axons of stellate cells in entorhinal cortex (EC) layer II, and the mossy fibers (MFs), the axons of dentate gyrus granule cells. The PP input is diffuse but weak, and conveys the compressed representations of neocortical activity from EC. The MF input is sparse but strong and selects subpopulations of pyramidal cells to establish nonoverlapping representations via strengthening of their recurrent collateral synapses. However, the MF input innervates more interneurons than pyramidal cells

Received 0ct. 8, 2008; revised 0ct. 23, 2008; accepted 0ct. 27, 2008.

This work was supported by National Institute of Neurological Disorders and Stroke Grant NS24288. We thank John Cavaretta for help with the interneuron reconstruction and technical support.

Correspondence should be addressed to Germán Barrionuevo, Department of Neuroscience, A210 Langley Hall, University of Pittsburgh, Pittsburgh, PA 15260. E-mail: german@pitt.edu.

D01:10.1523/JNEUROSCI.4848-08.2008

Copyright $\odot 2008$ Society for Neuroscience $\quad$ 0270-6474/08/2814042-14\$15.00/0
(Acsády et al., 1998), and although MF synapses onto CA3 interneurons have only one or two active zones (Acsády et al., 1998), the interneuron activation from the dentate gyrus is highly effective (Henze et al., 2002). When multiple cortical input patterns to CA3 arrive simultaneously, feedforward inhibition driven by MFs will limit the number of pyramidal cells activated by the same input. This synergistic excitatory action onto feedforward inhibitory interneurons could further increase the sparsity of the activity patterns (Mori et al., 2007) and the network storage capacity in CA3 (Treves and Rolls, 1992).

Like most cortical glutamatergic pathways, the MF input exhibits long-term potentiation (LTP) at synapses on pyramidal cells in response to high-frequency stimulation (HFS) (Jaffe and Johnston, 1990; Staubli et al., 1990; Zalutsky and Nicoll, 1990; Urban and Barrionuevo, 1996; Yeckel et al., 1999; Contractor et al., 2002). The resulting increase in pyramidal cell depolarization may promote the induction of Hebbian potentiation at their recurrent collateral synapses during the transfer and decorrelation of the compressed memory representations (Nakazawa et al., 2002). Such plasticity would allow future presentations of similar patterns to drive the same group of CA3 cells without the strong input from MFs. However, an increased gain in synaptic efficacy at MF synapses on pyramidal cells would likely be accompanied by degradation in pattern separation as many more CA3 pyramidal cells are activated. If MF input to pyramidal cells and feedfor- 


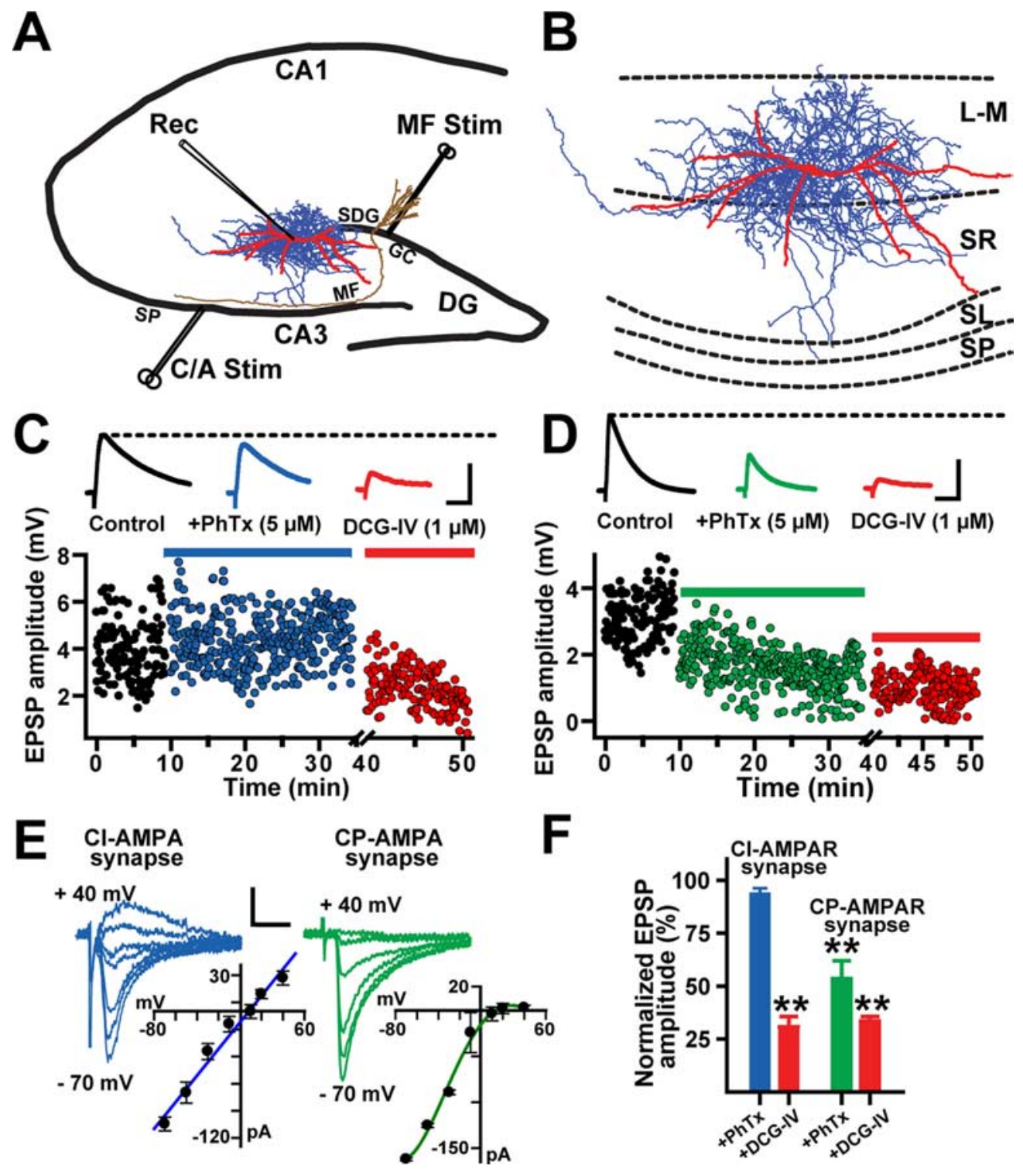

Figure 1. Composition of AMPARs at MF synapses on L-M interneurons. A, Schematic illustration of the hippocampal slice preparation showing the position of the concentric bipolar electrode in the SDG to stimulate MFs (MF Stim). In some experiments, a second bipolar electrode was placed in the s. pyramidale to activate the commissural/associational fibers (C/A Stim). The whole-cell recording pipette (Rec) was placed in the stratum lacunosum-moleculare (L-M) of area CA3. B, Computer reconstruction of a biocytin-filled L-M interneuron. Dendritic (red) and axonal arbors (blue) were reconstructed from serial coronal slices using the Neurolucida software. Abbreviations: SP, Stratum pyramidale; SL, stratum lucidum; SR, stratum radiatum; L-M, stratum lacunosum moleculare. C, Scatter plot from one representative experiment showing weak sensitivity of MF EPSPs $(\leq 10 \%)$ to PhTx ( $5 \mu \mathrm{M})$. MF EPSPs were reduced by DCG-IV (1 $\mu \mathrm{M})$ confirming their MF origin. Each dot represents a single MF EPSP evoked at $0.3 \mathrm{~Hz}$. The inset shows average MF EPSP traces (10 sweeps) from the same experiment. MF EPSPs were recorded in the presence of bicuculline (10 $\mu \mathrm{M})$ and D-AP5 $(50 \mu \mathrm{m})$. Calibration: $2 \mathrm{mV}, 25 \mathrm{~ms}$. D, In a second group of L-M interneurons, MF EPSPs were highly sensitive to PhTx ( $\geq 50 \%)$ and were also significantly reduced by DCG-IV (1 $\mu \mathrm{M})$, confirming their MF origin. The insets show average MF EPSP traces (10 sweeps) from the same experiment. Calibration: $2 \mathrm{mV}, 25 \mathrm{~ms}$. $\boldsymbol{E}$, Representative example of a linear current-voltage relationship $(I-V)$ for a CI-AMPAR MF synapse ( $r=0.97$; left) and a strongly inward-rectifying $I-V$ for a CP-AMPAR MF synapse (right). Calibration: $100 \mathrm{pA}, 10 \mathrm{~ms}$. $F$, Summary graph showing the number CI-AMPA MF synapses on L-M interneurons $(N=36)$ and CP-AMPA MF synapses $(N=14)$ and the average block by PhTx and DCG-IV. ${ }^{* *} p<0.001$ or higher statistical significance. Error bars indicate SEM.

ward interneurons simultaneously undergoes LTP, then the balance between excitation and inhibition is restored and the sparsity in the spatiotemporal segregation of pyramidal cell assemblies is maintained. Indeed, preservation of a narrow temporal window for synaptic integration after CA1 pyramidal cell LTP requires concurrent LTP at excitatory synapses on feedforward interneurons (Lamsa et al., 2005). However, extensive studies on CA3 feedforward inhibitory interneurons in the stratum (s.) lucidum have shown that the preferential form of plasticity at MF synapses is long-term depression (LTD) (Lawrence and McBain, 2003; Pelkey and McBain, 2007) (cf. Nicoll and Schmitz,
2005), which would further reduce pattern separation in the CA3 network. Given that interneuron classes in the hippocampus represent a diverse cell population (Freund and Buzsáki, 1996), the lack of MF LTP in stratum lucidum interneurons may be attributable to target cell-specific differences (Kullmann and Lamsa, 2007; Pelkey and McBain, 2008). In the present study, we performed a detailed analysis of the mechanisms underlying the induction of long-term plasticity at MF synapses on feedforward inhibitory interneurons with soma location in the stratum lacunosum-moleculare (L-M) of area CA3 in rat hippocampal slices. 


\section{Materials and Methods}

Slice preparation. Animal use was in accordance with the University Institutional Animal Care and Use Committee. Male Sprague Dawley rats (22 $\pm 4 \mathrm{~d}$ of age; Zivic-Miller Laboratories) were deeply anesthetized (Nembutal; $5 \mathrm{mg} / 100$ g body weight, i.p.) and perfused intracardially with a modified artificial CSF in which sucrose substituted for $\mathrm{NaCl}$ (concentrations in $\mathrm{mm}$ ): 230 sucrose, $1.9 \mathrm{KCl}, 1.2 \mathrm{Na}_{2} \mathrm{PO}_{4} \cdot 7 \mathrm{H}_{2} \mathrm{O}, 25.0$ $\mathrm{NaHCO}_{3}, 10.0$ glucose, $1.0 \mathrm{CaCl}_{2}, 4.0 \mathrm{MgCl}_{2}$ at $4^{\circ} \mathrm{C}$. After 1-2 min of perfusion, animals were decapitated and the brains were removed. Blocks of hippocampus were glued to the stage of a Leica VT1000S and cut in 350- $\mu$ m-thick sections. Slices were maintained for at least 60 $\mathrm{min}$ in an incubation solution of the following composition (in mM): $125 \mathrm{NaCl}, 2.0 \mathrm{KCl}, 1.2$ $\mathrm{NaH}_{2} \mathrm{PO}_{4}, 25 \mathrm{NaHCO}_{3}, 10$ glucose, $1 \mathrm{CaCl}_{2}$, and $6 \mathrm{MgCl}_{2}, \mathrm{pH} 7.3$ maintained with bubbled $\mathrm{O}_{2}(95 \%) / \mathrm{CO}_{2}(5 \%)$ at room temperature. The slices were then transferred to a submersion recording chamber and superfused at constant flow $(2.5 \mathrm{ml} / \mathrm{min})$ with the following solution (in mM): $125 \mathrm{NaCl}, 3 \mathrm{KCl}, 1.25 \mathrm{Na}_{2} \mathrm{HPO}_{4}, 25$ $\mathrm{NaHCO}_{3}, 2 \mathrm{CaCl}_{2}, 1 \mathrm{MgCl}_{2}, 10$ glucose, 0.01 (-)-bicuculline methobromide), and $0.05 \mathrm{D}-2$ amino-5-phosphonopentanoic acid (D-AP5). The temperature of the solution in the recording chamber was set at $33 \pm 1^{\circ} \mathrm{C}$.

Whole-cell recordings. Interneurons were identified visually with infrared video microscopy and differential interference contrast optics. Patch pipettes were pulled from borosilicate glass and had resistances of 3-6 M $\Omega$ when filled with a solution containing the following (in mM): $120 \mathrm{~K}$-methylsulfate, $10 \mathrm{NaCl}, 10 \mathrm{KCl}$, 10 HEPES, 0.5 EGTA, $4.5 \mathrm{Mg} \cdot \mathrm{ATP}, 0.3$ $\mathrm{Na}_{2} \cdot$ GTP, 14 phosphocreatine. Biocytin $(0.1 \%)$ was routinely added to the pipette solution to allow subsequent morphological identification and reconstruction of the interneurons (see Fig. $1 A, B)$. For 1,2-bis(2-aminophenoxy)ethane$N, N, N^{\prime}, N^{\prime}$-tetra-acetic acid (BAPTA) experiments, the final K-methylsulfate concentration was decreased to 75 , and $20 \mathrm{~mm}$ tetrapotassium BAPTA $\left(4 \mathrm{~K}^{+}\right.$-BAPTA; Sigma-Aldrich $)$was added. Osmolarity was routinely checked and adjusted to 295-300 mOsm with pH 7.2-7.3.

Electrophysiological measurements of membrane properties. The membrane potential was measured immediately after cell break-in. After the membrane potential of the cell was stabilized in current clamp, a series of inward and outward current steps (500 ms duration; $30 \mathrm{pA}$ increments) were injected via the whole-cell pipette to assess input resistance $\left(R_{\mathrm{i}}\right)$, action potential (AP) amplitude, and afterhyperpolarization (AHP) amplitude. $R_{\mathrm{i}}$ was calculated as the slope of linear fit between voltage and injected current AHP amplitude was measured from AP threshold to the hyperpolarization peak. Experiments were analyzed only if the access resistance was $<10 \mathrm{M} \Omega$ or it changed $<15 \%$ of the initial value. Access resistance was monitored throughout the length of experiments.

Stimulation techniques. MF synaptic responses were evoked by extracellular stimulation using concentric bipolar electrodes (12.5 $\mu \mathrm{m}$ inner pole diameter, $125 \mu \mathrm{m}$ outer pole diameter; FHC) positioned on the suprapyramidal blade of the dentate gyrus (SDG) (Calixto et al., 2008) (see Fig. 1A). In some experiments, a second stimulating electrode was
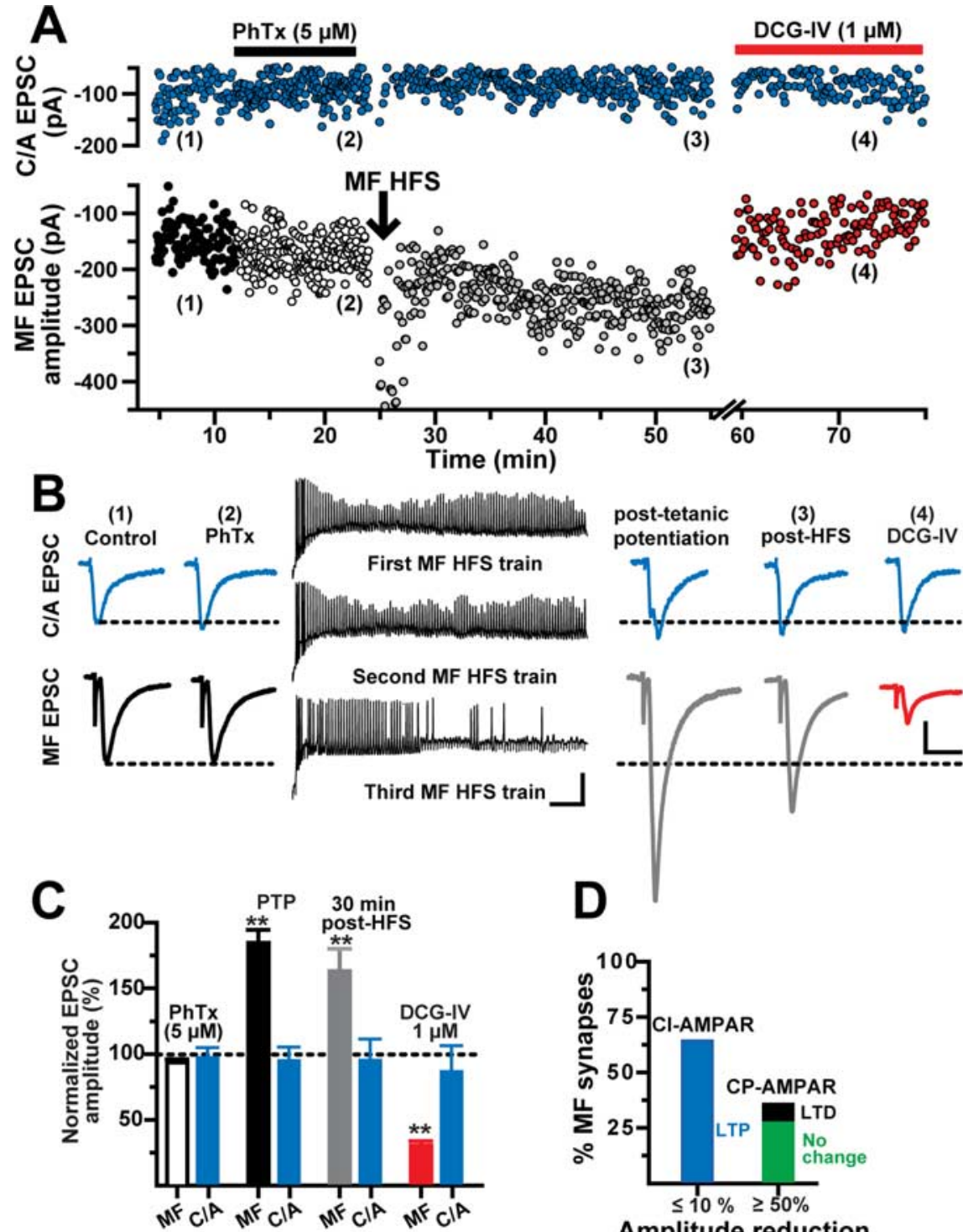

Amplitude reduction

Figure 2. MF LTP is input specific and expressed at predominantly CI-AMPAR synapses. $A$, Representative experiment showing the time course of MF and C/A EPSC amplitudes before (1), during PhTx (2), after HFS of MFs (3), and during DCG-IV (4). Each circle represents a single EPSC recorded at $0.2 \mathrm{~Hz}$. MF EPSCs were weakly $(<10 \%)$ sensitive to $\mathrm{PhTx}(5 \mu \mathrm{M})$. LTP was induced at MFs but ot C/A synapses. $\boldsymbol{B}$, Left and right traces, Average MF and C/A EPSCs (10 consecutive sweeps) from the same experiment before and after HFS of MFs, respectively. Calibration: $50 \mathrm{pA}, 10 \mathrm{~ms}$. Middle traces, Membrane voltage responses show robust spiking during HFS of MFs. Calibration: $25 \mathrm{mV}, 100 \mathrm{~ms}$. C, Summary of the changes in MF and C/A EPSC amplitude ( $N=11$ ) during PTP, at $\leq 10 \%)$. $D$, Bar graph summarizing the proportion of MF synapses containing predominantly Cl-AMPARs $(N=11)$ and $(\mathrm{P}$ AMPARs $(N=7)$. All of the Cl-AMPAR synapses underwent MF LTP. In contrast, in MF synapses predominantly containing CP-AMPAR the isolated CI-AMPAR-mediated response was unchanged after MF HFS $(N=5)$ or exhibited MFLTD $(N=2)$. ${ }^{* *} p<$ 0.001 or higher statistical significance.

placed in the s. pyramidale of area CA3 to activate the commissural/ associational (C/A) fibers. Stimulation consisted of single monopolar pulses $(100-300 \mu \mathrm{A} ; 50-100 \mu$ s duration) at $0.25 \mathrm{~Hz}$. To reduce the probability of antidromic activation of CA3 pyramidal cells via stimulation of their axon collaterals, we used low current intensities, which resulted in composite EPSP with amplitudes $<30 \%$ of the threshold amplitude required to evoke action potentials in the recorded interneurons. Paired-pulse facilitation (PPF) (60 ms ISI) was assessed in currentclamp mode. PPF was calculated as the paired-pulse ratio (PPR) of the amplitude of the second EPSP to that of the first in the pair.

Identification of MF synaptic input. Current- and voltage-clamp recordings were obtained with an Axoclamp-1D amplifier (Molecular Devices) in the presence of (-)-bicuculline methiodide (10 $\mu \mathrm{M})$ and D-AP5 
A
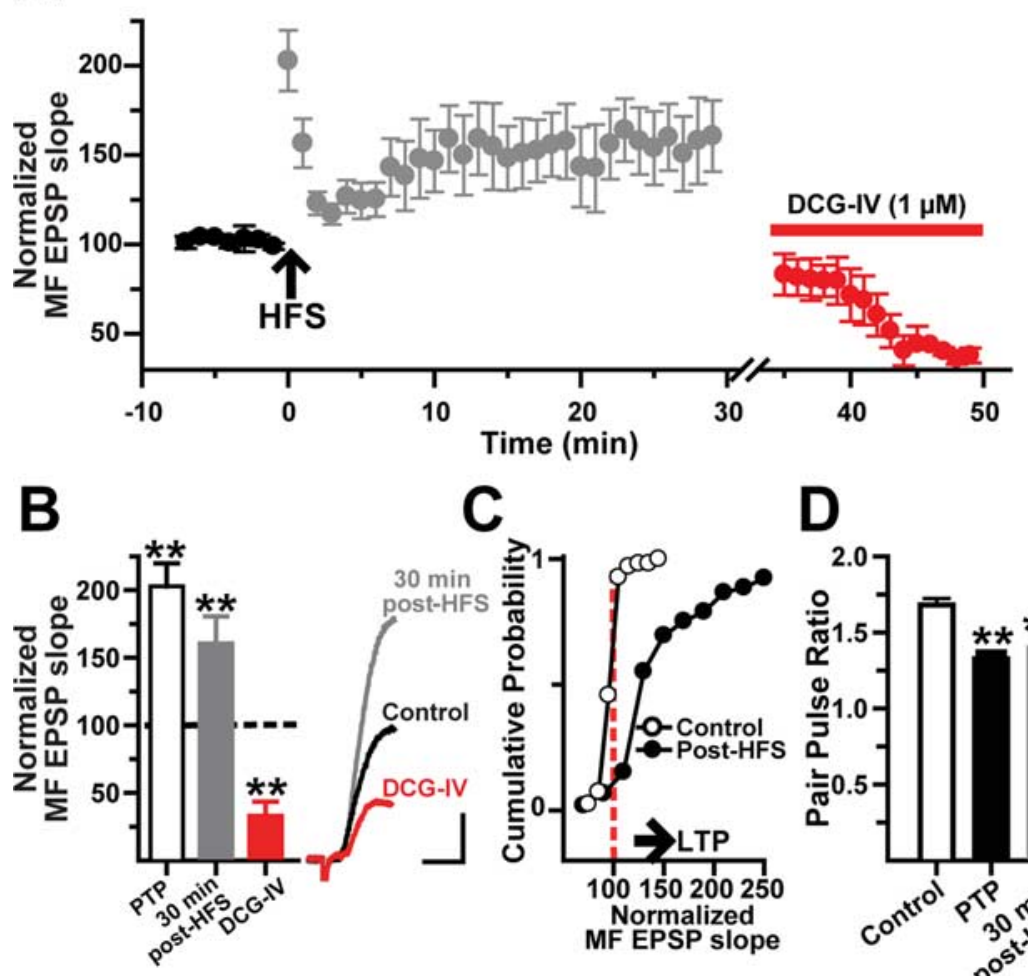

D

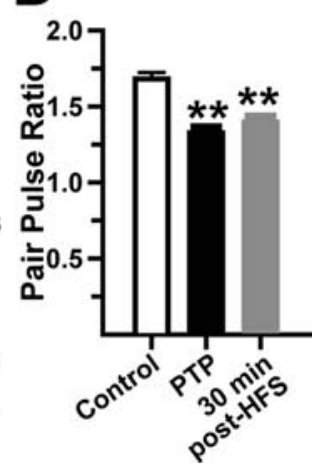

Figure 3. MFLTP is accompanied by a decrease in paired-pulse facilitation. $\boldsymbol{A}$, Time course of normalized MF EPSP slopes before and after the induction of LTP. Each circle represents average \pm SEM from 25 interneurons. The MF origin of the EPSPs was confirmed by DCG-IV application at the end of the experiment. $B$, Bar graph $(N=25)$ summarizes the changes in MF EPSP slope during PTP, at 30 min after HFS, and in the presence of DCG-IV. The inset shows the average MF EPSP slope (10 sweeps) from one representative cell showing LTP and DCG-IV sensitivity. Calibration: $2 \mathrm{mV}, 5 \mathrm{~ms}$. C, Cumulative probability distribution of normalized EPSP slopes before HFS (open circles) and during LTP measured after the first 5 min after HFS to exclude PTP (closed circles) for the same cells. Each point represents the magnitude of change relative to a normalized baseline computed from the average EPSP slope. The start of the horizontal arrow corresponds to the minimum criteria for LTP (stable synaptic enhancement $>25 \%$ above baseline for $30 \mathrm{~min})$. D, Decrease in paired-pulse facilitation during PTP and LTP. ${ }^{* *} p<0.001$ or higher statistical significance. Error bars indicate SEM.

$(50 \mu \mathrm{M})$ to block $\mathrm{GABA}_{\mathrm{A}}$ and NMDA receptor (NMDAR)-mediated responses, respectively [supplemental Table 1 (available at www. jneurosci.org as supplemental material) summarizes the properties MF EPSPs on L-M interneurons]. The group II metabotropic glutamate receptor agonist $\left(2 S, 2^{\prime} R, 3^{\prime} R\right)-2-\left(2^{\prime}, 3^{\prime}\right.$-dicarboxycyclopropyl)glycine (DCG-IV) $(1 \mu \mathrm{M})$ was applied at the end of every experiment to confirm the MF origin of the EPSP (see Fig. 1C,D). Although DGC-IV inhibition of MF transmission in pyramidal cells is consistently complete ( $\geq 90 \%)$ (Kamiya et al., 1996), it is variable in interneurons (Alle et al., 2001; Lawrence and McBain, 2003; Calixto et al., 2008). Therefore, synaptic responses were classified to be of MF origin if their DCG-IV sensitive was $>50 \%$ inhibition (Lawrence and McBain, 2003).

Criteria for LTP and LTD. LTP and LTD were induced by HFS consisting of three trains of 100 pulses each at $100 \mathrm{~Hz}$, repeated every 10 s paired with a postsynaptic depolarizing current step $(30 \pm 0.6 \mathrm{pA})$ in currentclamp mode. This induction protocol produced strong postsynaptic firing. Changes in the strength of the compound EPSP were assessed by measuring the initial slope of the EPSP waveform (20-80\% from the EPSP onset). Minimally evoked EPSPs and EPSCs were quantified measuring peak amplitude of the waveform. We defined LTP as stable potentiation of $>25 \%$ with respect to baseline for at least $30 \mathrm{~min}$ after HFS (Lamsa et al., 2005). LTD was defined as a reduction of synaptic efficacy of $<25 \%$ for at least $30 \mathrm{~min}$ after HFS. Values from each experiment normalized to its pre-HFS baseline magnitude for comparison across experiments. Signals were low-pass filtered at $5 \mathrm{kHz}$, digitized at $10 \mathrm{kHz}$, and stored on disk for off-line analysis. Data acquisition and analysis were performed using customized LabView programs (National Instruments)

Minimal stimulation techniques. These experiments were performed and analyzed as previously reported by others (Stevens and Wang, 1994; Xiang et al., 1994; Perez et al., 2001; Lawrence et al., 2004). To identify putative single MF synaptic connections, the stimulus strength was gradually reduced until no EPSPs were detected and then increased in increments of $5 \mu \mathrm{A}$ until at an abrupt stimulation threshold at which responses were reliably evoked at a failure rate between 30 and $60 \%$ (failures were identified by visual inspection). Cells were held at $69 \pm 0.1 \mathrm{mV}$ and access resistance was monitored every $10 \mathrm{~min}$ throughout the experiments. MF EPSPs were included according to the following criteria: invariant EPSPs latency and shape, and monoexponential EPSP decay. Under these conditions, we assumed that the EPSP recording was predominantly monosynaptic and attributable to the activation of a single MF fiber. Minimally, EPSPs were evoked at $0.25 \mathrm{~Hz}$. After a $5 \mathrm{~min}$ stable baseline period, LTP was induced by injecting a postsynaptic depolarizing current step $(30 \pm 0.6 \mathrm{pA})$ that evoked action potentials when paired to the HFS train. EPSPs were recorded for at least $30 \mathrm{~min}$ after HFS, and then DCG-IV was applied to confirm their MF origin.

Statistical analysis. Group measures are expressed as means \pm SEM. To determine the statistical significance of the changes in EPSP amplitude, the mean EPSP amplitude baseline was compared with the mean EPSP amplitude at 25-30 min after HFS. Normality of the populations were tested with Kolmogorov-Smirnov test $(p<0.05)$, followed by one-way ANOVA and Student-Newman-Keuls all-pairwise comparisons $(p<0.05)$. In all cases, differences were considered significant if $p<\alpha=0.05$.

Drugs. D-AP5, (-)-bicuculline methobromide, DCG-IV, (1)-2-methyl-4-carboxyphenylglycine (LY367385), and 2-methyl-6-(phenylethynyl)pyridine hydrochloride (MPEP) were purchased from Tocris. Philanthotoxin 433 , BAPTA, nimodipine, and low-molecular-weight heparin $(\mathrm{H}-$ 3400) were acquired from Sigma-Aldrich. Purified Ryanodine was obtained from BIOMOL Research Laboratories.

Morphological reconstruction. After recordings, slices were fixed in cold $4 \%$ paraformaldehyde for $72 \mathrm{~h}$, transferred into an antifreeze solution (1:1 mixture of glycerol and ethylene glycol in $0.1 \mathrm{M}$ phosphate buffer), and stored at $-80^{\circ} \mathrm{C}$. Slices were then cut into $60 \mu \mathrm{m}$ sections on a vibratome, reacted with $1 \% \mathrm{H}_{2} \mathrm{O}_{2}$, and placed in blocking serum with $0.5 \%$ Triton X-100 for $2 \mathrm{~h}$ at room temperature. Biocytin-labeled neurons were incubated with $\mathrm{ABC}$-peroxidase and developed using the $\mathrm{Ni}$ enhanced $\mathrm{DAB}$ (3,3'-diaminobenzidine) chromogen. Interneurons were reconstructed using the Neurolucida tracing system (MicroBrightField) on a Axioplan 2 Zeiss microscope equipped with differential interference contrast, a $100 \times$ (numerical aperture, 1.4) planapochromatic lens and additional Optovar magnification of $1.6 \times$ (final optical magnification, $1600 \times$; screen magnification, $7200 \times$ ). For the reconstructions, all sections containing the cell were used.

\section{Results}

AMPA receptor composition of the MF synapse on

L-M interneurons

Visually guided whole-cell recordings in combination with biocytin cell labeling were obtained from the somata of interneurons positioned in the s. lacunosum-moleculare at $\sim 278 \pm 20 \mu \mathrm{m}$ 
from the boundary between s. pyramidale and s. lucidum, $150 \pm 20 \mu \mathrm{m}$ from the SDG (Fig. $1 A$ ), and 60-100 $\mu \mathrm{m}$ below the slice surface. Post hoc analysis of labeled interneurons revealed that somata were positioned at $-2.45 \pm 0.67 \mathrm{~mm}$ from bregma, and $2.33 \pm 0.16 \mathrm{~mm}$ from midline (G. A. Ascoli, K. M. Brown, E. Calixto, J. P. Card, and G. Barrionuevo, unpublished observations). L-M interneurons gave rise to complex axonal arbors, which extended beyond the somatic layer position into the stratum radiatum and stratum lucidum (Fig. 1 $A, B$ ). Most dendritic branches exhibited a conspicuous lack of spines. Some of the dendrites branches in the s. lacunosum-moleculare course near the SDG where they could receive input from the MF axons traveling to the s. lucidum or from MF collateral plexuses in the hilus of the dentate gyrus (Claiborne et al., 1986; Acsády et al., 1998). In addition, these interneurons also may receive $\mathrm{MF}$ input from synapses en passant in the $s$. lucidum or from filipodial extensions arising from MF boutons on CA3 pyramidal cells in the s. pyramidale (Acsády et al., 1998). However, our previous observations suggest that MF input elicited from the SDG stimulation site is predominantly evoked from axonal projections confined to dendrites near the hilus (Calixto et al., 2008). We previously reported the passive and active membrane properties of L-M interneurons (Calixto et al., 2008).

In hippocampal pyramidal cells, AMPA receptors (AMPARs) are calciumimpermeable (CI) composed of heteromeric GluR1, GluR2, and GluR3 subunits, whereas hippocampal interneurons also express GluR2-lacking calcium-permeable (CP) AMPARs (Dingledine et al., 1999; Tóth et al., 2000; Bischofberger and Jonas, 2002). The GluR2-lacking AMPARs are selectively blocked by the extracellular application of the polyamine toxin philanthotoxin (PhTx). Based on the sensitivity of MF EPSPs to PhTx, L-M interneurons were classified in two subpopulations (Fig. $1 F)$. In 18 of 28 cells, PhTx $(5 \mu \mathrm{M})$ produced a small $(\leq 10 \%)$ but significant reduction in EPSP amplitudes ( $93 \pm 2.6 \%$ of baseline; $p<0.05$, one-way ANOVA) (Fig. $1 C$; supplemental Table 1 , available at www.jneurosci.org as supplemental material). EPSPs were subsequently depressed by DCG-IV ( $1 \mu \mathrm{M}$; $66.2 \pm 4.6 \%$ inhibition; $p<0.001$, one-way ANOVA) (Fig. $1 C$ ) confirming that they were originated from MF synapses (Tóth et al., 2000; Alle et al., 2001; Calixto et al., 2008). These EPSPs were classified as produced by CI-AMPARs (Lei and McBain, 2002). In the 10 remaining cells, MF EPSP amplitudes were substantially reduced $(\geq 50 \%)$ by $\operatorname{PhTx}(53.3 \pm 8.4 \%$ of baseline) (Fig. $1 D, F)$ and further depressed by DCG-IV (63.2 $\pm 8 \%$ inhibition; $p<$ Error bars indicate SEM.
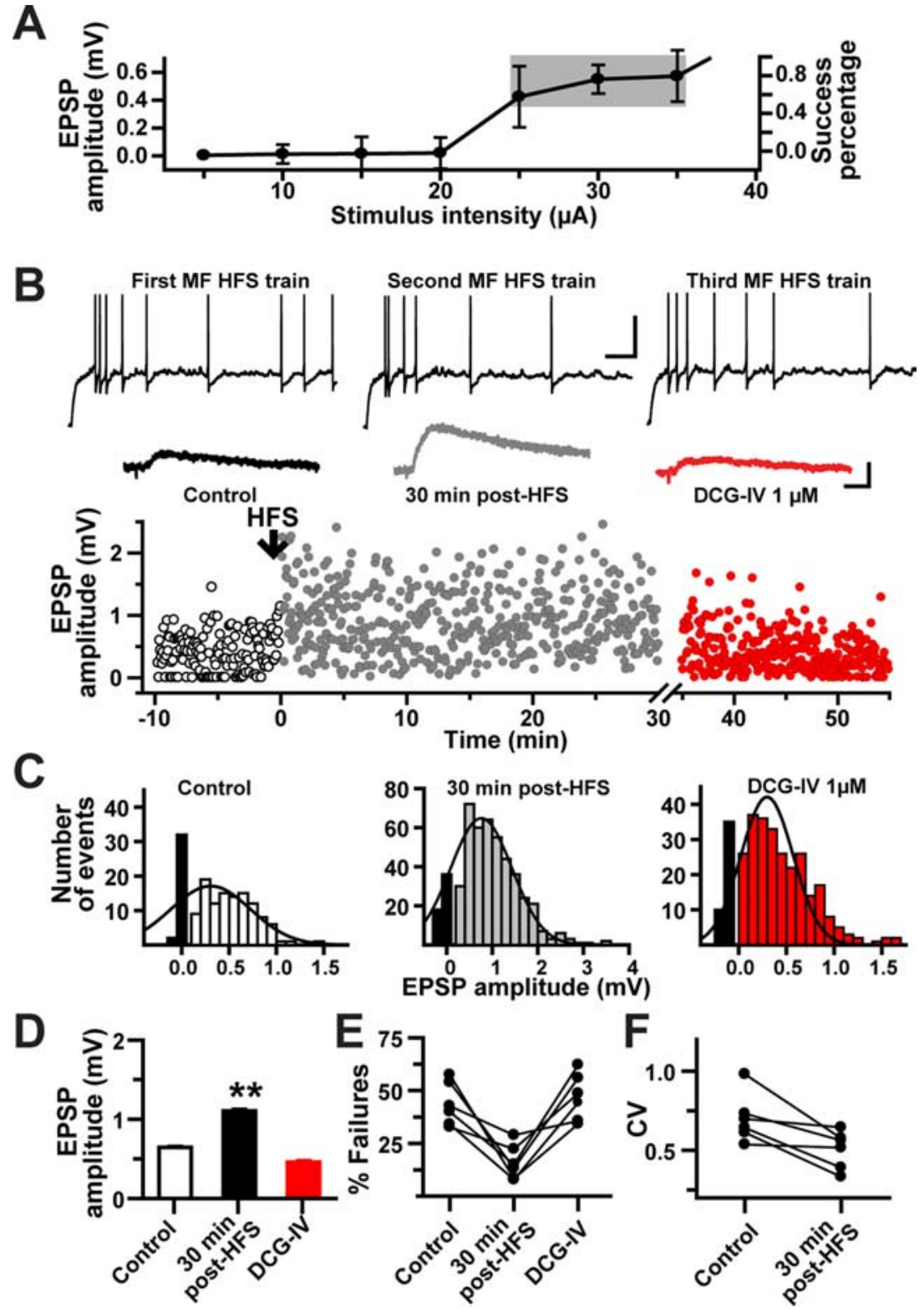

Figure 4. LTP of minimally evoked MF EPSP. A, Putative single-fiber MF EPSPs were identified by plotting EPSP amplitudes as a function of stimulus intensity. The gray area indicates the typical range of stimulation intensity, which was kept constant throughout the experiment. This stimulation intensity produced $30-60 \%$ of failure rate of the evoked MF EPSPs. $\boldsymbol{B}$, Scatter plot of minimal MF EPSP amplitudes from one representative cell showing the occurrence of LTP after the pairing of HFS with postsynaptic depolarization. Each dot in the scatter plot represents a single MF EPSP evoked at $0.3 \mathrm{~Hz}$. Inset, Top traces show postsynaptic spiking during MF HFS. Calibration: $25 \mathrm{mV}, 100 \mathrm{~ms}$. Bottom traces are average minimal MF EPSPs (10 consecutive sweeps) exhibiting LTP at 30 min after HFS and the subsequent amplitude reduction by DCG-IV confirming their MF origin. Calibration: 0.5 $\mathrm{mV}, 10 \mathrm{~ms}$. C, Amplitude histograms of the normalized distribution of minimal MF EPSPs from the same cell. The black bars represent the number of failures. $D$, Summary bar graph for all cells $(N=6)$ depicting LTP of minimal MFEPSPs and their inhibition by DCG-IV. $\boldsymbol{E}$, The increase in the potency of MF synaptic transmission during LTP was associated with a significant decrease in the failure rate. $\boldsymbol{F}$, Likewise, there was a significant decrease in the CV during MF LTP. ${ }^{* *} p<0.001$ or higher statistical significance.

0.001, one-way ANOVA). These MF EPSPs were categorized as originating from CP-AMPARs (Lei and McBain, 2002). These two subpopulations of interneurons appear to coexist in close proximity to each other within the stratum lacunosum moleculare. In some experiments, we also assessed the current-voltage relationship $(I-V)$ of AMPAR EPSCs. In agreement with previous reports (Tóth and McBain, 1998; Laezza et al., 1999), the PhTx-insensitive AMPAR EPSCs exhibited near linear $I-V$ rela- 


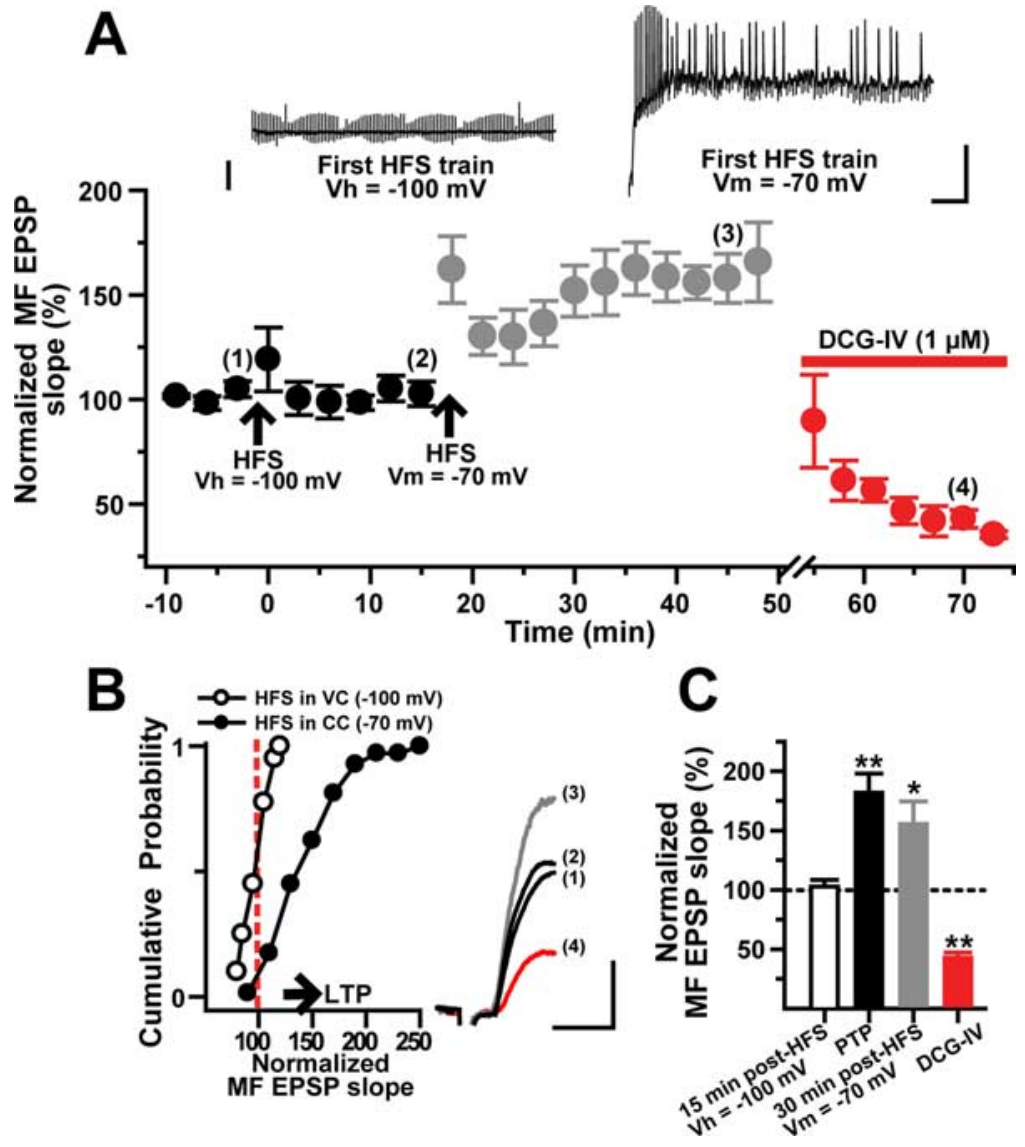

Figure 5. The induction of MF LTP in L-M interneurons requires simultaneous afferent stimulation and postsynaptic depolarization. $A$, HFS applied while cells $(N=8)$ were held in voltage clamp at $-100 \mathrm{mV}$ failed to induce LTP. Subsequent HFS applied in current-clamp recordings $(-70 \mathrm{mV})$ evoked robust LTP. MF EPSPs were sensitive to DCG-IV. Inset, The left trace is the membrane current response from a representative cell held in voltage-clamp conditions showing the absence of postsynaptic spiking during the HFS. The right trace is the membrane voltage response from the same cell in current-clamp conditions displaying action potential discharge throughout the HFS. Calibration: $25 \mathrm{mV}, 100 \mathrm{~ms}$. $\boldsymbol{B}$, Cumulative probability distribution of normalized MF EPSP slopes for the same cells showing absence of LTP (HFS in voltage-clamp mode) and the occurrence of LTP (HFS in current-clamp mode) in the same cells. The start of the horizontal arrow corresponds to the minimum criteria for LTP (stable synaptic enhancement $>25 \%$ above baseline for $30 \mathrm{~min}$ ). The inset shows average MF EPSP slopes ( 10 consecutive sweeps) from a representative experiment obtained at the time points indicated by the numbers in $\boldsymbol{A}$. Calibration: $2 \mathrm{mV}, 5 \mathrm{~ms}$. C, Population data $(N=10)$ showing lack of MFLTP when HFS was applied in voltage-clamp conditions. In the same cells, MFLTP was induced by a second HFS delivered during current-clamp recordings. ${ }^{*} p<0.05$ and ${ }^{* *} p<0.001$ or higher statistical significance. Error bars indicate SEM.

tionships, whereas the PhTx-sensitive AMPAR EPSCs showed a strong inward rectification (Fig. 1E).

\section{MF LTP is input specific and induced at predominantly CI-AMPAR synapses}

Previous studies demonstrated that MF LTP in pyramidal cells is input specific (Zalutsky and Nicoll, 1990) and induced at synapses containing CI-AMPARs (Tóth et al., 2000) in the absence of NMDAR activation (Harris and Cotman, 1986). Given the considerable proportion of MF synapses that were weakly sensitive to the PhTx block (62\%), we postulated that CI-AMPARs on L-M interneurons may be capable of supporting input-specific, NMDAR-independent MF LTP. To test this hypothesis, MF EPSCs and C/A (Fig. 1A) EPSCs were recorded simultaneously $\left(V_{\mathrm{h}}\right.$ $=69 \pm 3 \mathrm{mV})$ in the presence of $\operatorname{PhTx}(5 \mu \mathrm{M})$ in perfusion bath. In 11 of 18 cells ( $61 \%$ of total), PhTx modestly reduced MF EPSC amplitudes (93.5 $\pm 3 \%$ of baseline; $p<0.05$, one-way ANOVA) (Fig. $2 A, C$ ) but did not affect C/A EPSC amplitudes (97.2 $\pm 8 \%$ of baseline; $p>0.5$, one-way ANOVA) (Fig. $2 A, C$ ). At the end of the PhTx application, HFS was delivered to the MF input. The depolarized interneuron fired a train of action potentials during each of the HFS trains. After the HFS, the isolated CIAMPAR component of the MF EPSC exhibited a robust posttetanic potentiation (PTP) $(203.3 \pm 6.4 \%$ of baseline $)$ followed by a sustained LTP $(163.1 \pm 17 \%$ of baseline at $30 \mathrm{~min}$ after HFS; $p<0.001$, oneway ANOVA; $N=11)$. Bath application of DCG-IV $(1 \mu \mathrm{M})$ confirmed that the EPSCs were generated by MF synapses (67.3 \pm $10.8 \%$ inhibition) (Fig. $2 \mathrm{~B}, \mathrm{C}$ ). In contrast, $\mathrm{C} / \mathrm{A}$ EPSCs were not affected by the HFS of MFs ( $95 \pm 10.5 \%$ at 1 min after HFS, and $95.2 \pm 16 \%$ at 30 min after HFS; $p>0.5$, one-way ANOVA; $N=11$ ) and were insensitive to DCG-IV (3.4 $\pm 12.4 \%$ inhibition) (Fig. 2A-C). Collectively, these data indicate that MF LTP in L-M interneurons is input specific, and not the consequence of contamination from NMDARindependent LTP at C/A synapses on the recorded cell. Additional data obtained in our laboratory show that similar HFS delivered to the C/A input to L-M interneurons in the presence of D-AP5 induced LTD $(57.2 \pm 6.8 \%$ of baseline; $N=3)(\mathrm{T}$. Perez-Rosello and G. Barrionuevo, unpublished observations).

In 7 of 18 interneurons treated with PhTx, MF EPSCs were substantially reduced (53.3 $\pm 8.4 \%$ of baseline) and classified as predominantly containing CPAMPARs. After HFS, the isolated CIAMPAR-mediated responses in 5 of 7 cells (28\%) exhibited a smaller PTP (135.5 \pm $15.7 \%$ relative to $\mathrm{PhTx}$ baseline; $p<$ 0.002 ) and remained unchanged at $30 \mathrm{~min}$ after HFS (95.9 $\pm 6 \%$ ) despite strong postsynaptic firing during the HFS (supplemental Fig. 1, available at www. jneurosci.org as supplemental material). In the remaining two interneurons (11\%), the isolated CI-AMPAR-mediated MF EPSC underwent LTD $(73.7 \pm 8.2 \%$ at $30 \mathrm{~min}$ after HFS; $p<0.0001$, unpaired $t$ test) (supplemental Fig. 2, available at www.jneurosci.org as supplemental material).

We further characterize the magnitude and time course of MF LTP in L-M interneurons in current-clamp conditions $\left(V_{\mathrm{m}}=\right.$ $69.6 \pm 1 \mathrm{mV}$ ) (supplemental Table 1, available at www. jneurosci.org as supplemental material). In the majority of these cells (25 of 32; 78\%), the initial slope of the MF EPSP showed robust PTP $(202.8 \pm 17 \%$ of baseline $)$ followed by a sustained LTP $(160.6 \pm 19 \%$ at 30 min after HFS; $N=25$ of $32 ; p<0.001$, one-way ANOVA) (Fig. 3A-C). DCG-IV subsequently reduced the EPSP slopes by $64.7 \pm 4 \%(p<0.001$, one-way ANOVA). We also measured PPR during baseline $(1.73 \pm 0.05)$, at 1 min after HFS (1.52 \pm 0.03 ; one-way ANOVA, $p<0.001)$, and at $30 \mathrm{~min}$ after HFS (1.48 \pm 0.04; one-way ANOVA, $p<0.05$ ) (Fig. $2 D)$. The reduction in PPF during LTP is suggestive of a presynaptic expression of MF LTP in L-M interneurons, as previously shown for MF LTP in pyramidal cells (Staubli et al., 1990; Zalutsky and Nicoll, 1990; Xiang et al., 1994; Sokolov et al., 2003) and dentate 
gyrus basket cells (Alle et al., 2001). In the remaining seven cells, MF EPSP slopes remained unchanged after HFS $(N=5 ; 16 \%$ of total) or underwent LTD $(N=2 ; 6 \%$ of total).

\section{LTP of minimally evoked MF EPSPs}

Another possible source of interpretational error is that the potentiation observed in L-M interneurons may have resulted from the recruitment of additional CA3 pyramidal cells because of the parallel induction of MF LTP in CA3 pyramidal cells. Hence, HFS potentiated the MF input and also the synaptic drive from the polysynaptic recurrent collateral input. To reduce the likelihood of polysynaptic contamination, we examined changes in synaptic efficacy evoked by minimal stimulation (Fig. 4A), which putatively activates single axons that terminate onto L-M interneurons (Stevens and Wang, 1994; Xiang et al., 1994; Perez et al., 2001; Lawrence et al., 2004). During baseline period, minimal stimulation elicited MF EPSPs with average amplitudes of $0.66 \pm 0.02$ $\mathrm{mV}$ (failures included). HFS was paired with a postsynaptic depolarizing current pulse $(30 \pm 0.6 \mathrm{pA})$, and in all cases the cells fired action potentials in response to the HFS (Fig. $4 B$, inset). This pairing protocol yielded a sustained increase in EPSP amplitude in six of nine cells $(1.10 \pm 0.03$ $\mathrm{mV}$ at 25-30 min after HFS; $p<0.001$, one-way ANOVA) (Fig. $4 B, C$ ), and no change in the remaining three cells $(0.64 \pm$ $0.07 \mathrm{mV})$. LTP induced with the minimal stimulation protocol was associated with a decrease in both failure rate $(30-65 \%$ during baseline; $8-30 \%$ at $25-30 \mathrm{~min}$ after HFS) and coefficient of variation $(\mathrm{CV})(0.7 \pm 0.06$ during baseline; $0.5 \pm 0.05$ at $25-30$ min after HFS; $N=6 ; p<0.02$, one-way ANOVA) (Fig. $4 D-F$ ). After 30 min of sustained LTP, the application of DCG-IV $(1 \mu \mathrm{M})$ decreased EPSP amplitude to $0.45 \pm 0.03 \mathrm{mV}(N=6)$ and increased the failure rate by $45-60 \%$. Together, these data indicate that LTP was induced directly at MF synapses on L-M interneurons and resulted from an increase in the probability of transmitter release from MF presynaptic terminals.

\section{MF LTP requires postsynaptic depolarization and calcium elevation}

To test the involvement of postsynaptic activation in the induction of LTP, we applied HFS to MFs while simultaneously voltage clamping the membrane potential of the cell at $-100 \mathrm{mV}$ to prevent postsynaptic spiking (Fig. $5 \mathrm{~A}$, inset). Under these conditions, no significant changes after HFS were detected in the EPSP slope compared with baseline responses $(98.7 \pm 8 \%$ at $5 \mathrm{~min}$ after HFS; $p>0.05 ; 102 \pm 6 \%$ at 15 min after HFS; $p>0.05 ; N=10$ ) (Fig. $5 A)$. A subsequent HFS applied in current-clamp mode $\left(V_{\mathrm{m}}\right.$ $=69 \pm 3 \mathrm{mV}$ ) elicited a pronounced and sustained increase in the initial EPSP slope $(165.7 \pm 19 \%$ at $30 \mathrm{~min}$ after HFS; $N=6)$ (Fig. $4 A-C)(p<0.001$, one-way ANOVA). Application of DCG-IV inhibited the initial slope of the potentiated EPSPs by $64.6 \pm 6 \%$ (Fig. $5 A, C$ ).
It has been shown that elevation of postsynaptic $\mathrm{Ca}^{2+}$ influx is a necessary condition for the induction of MF LTP in pyramidal cells (Jaffe and Johnston, 1990; Yeckel et al., 1999; Sokolov et al., 2003) (but see Zalutsky and Nicoll, 1990) and basket cells in the dentate gyrus (Alle et al., 2001). To investigate whether MF LTP in L-M interneurons depends on a rise in postsynaptic $\left[\mathrm{Ca}^{2+}\right]$ elicited by the HFS, the patch pipette was filled with an internal solution containing the fast calcium chelator BAPTA $(20 \mathrm{~mm})$. BAPTA loading did not significantly affect the EPSP kinetics during the baseline period (supplemental Table 1, available at www.jneurosci.org as supplemental material) but significantly reduced the area of the $\mathrm{Ca}^{2+}$-dependent afterhyperpolarization potential (AHP) after trains of action potentials $(77.4 \pm 4.6 \%$ of baseline; $p<0.000$, unpaired $t$ test; $N=10$ ) (Fig. $6 B$ ). BAPTA loading did not affect PTP of the EPSP slope $(202.8 \pm 16.9 \%$ in control cells; $N=31 ; 216.3 \pm 42.3 \%$ in BAPTA loaded cells; $p>$ 0.05 , one-way ANOVA; $N=11$ ) but prevented LTP induction in 11 of 15 cells $(96.9 \pm 14 \%$ at $5 \mathrm{~min}, p>0.05 ; 90.4 \pm 11 \%$ at 30 min after HFS, $p>0.05$, one-way ANOVA) (Fig. 6A,C). The application of DCG-IV $(1 \mu \mathrm{M})$ confirmed the MF origin of the EPSPs ( $62 \pm 9 \%$ inhibition; $p<0.001$, one-way ANOVA) (Fig. $6 A, C)$. In the remaining four cells, BAPTA loading failed to block LTP $(159.5 \pm 8.6 \%$ of baseline at $30 \mathrm{~min}$ after HFS; $p<0.001$, unpaired $t$ test; $66.2 \pm 2.57 \%$ inhibition by DCG-IV) (data not shown). It has been reported that, in pyramidal cells, block of MF LTP induced with similar HFS trains requires 30-50 mM BAPTA concentrations (Yeckel et al., 1999). Failure to prevent LTP in 

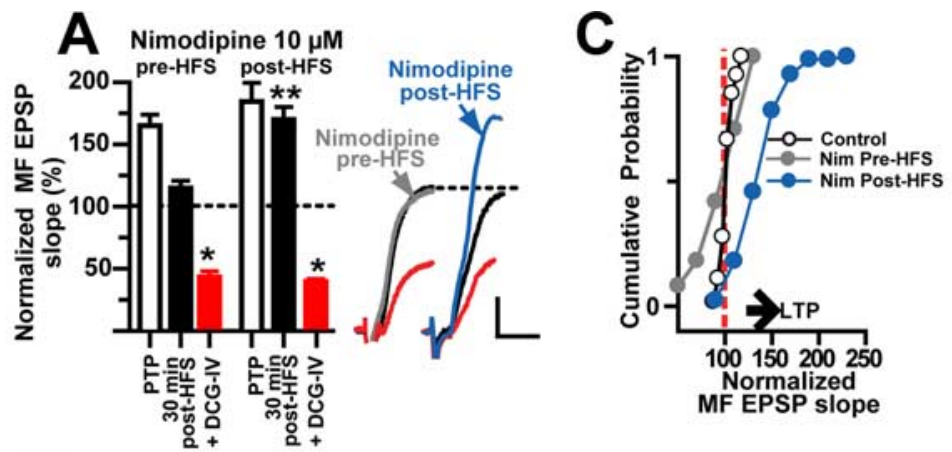

B
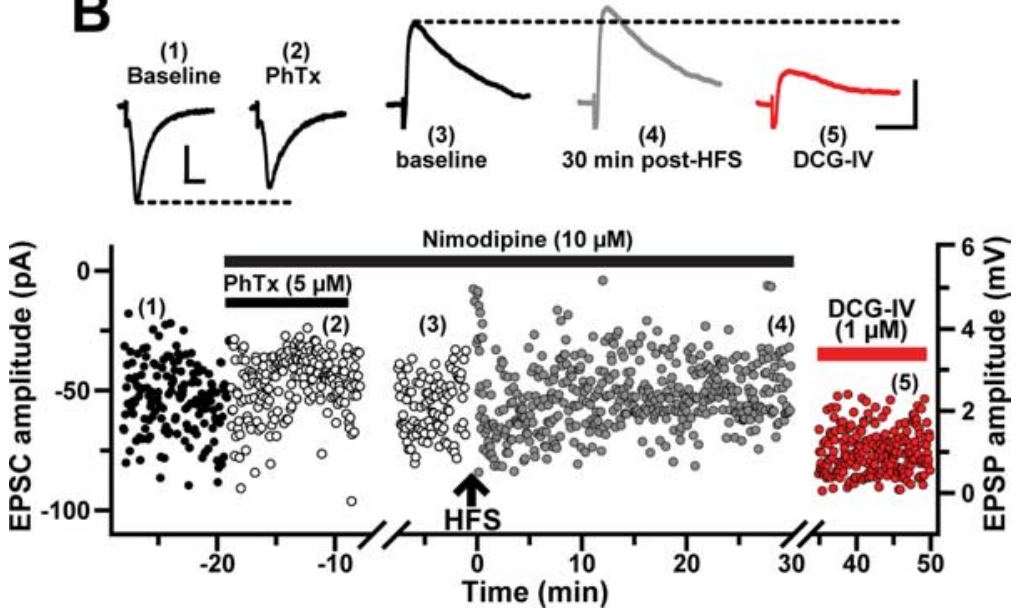

Figure 7. The induction of MF LTP requires L-type $\mathrm{Ca}^{2+}$ channel activation. $A$, Time course of normalized MF EPSP slopes demonstrating that nimodipine $(10 \mu \mathrm{M})$ added before HFS blocked LTP $(N=9)$ but did not affect LTP maintenance when it was included in the bath solution 5-10 min after HFS $(N=5)$. Summary bar graph for the same cells showing the effect of nimodipine added to the bathing solution before or after HFS. The EPSP amplitude was similarly reduced by DCG-IV in both conditions. The inset depicts average MF EPSP slopes (10 consecutive sweeps) from two representative experiments. Calibration: $2 \mathrm{mV}, 5 \mathrm{~ms} . \boldsymbol{B}$, Representative experiment showing the time course of MF amplitude before (1), in $\mathrm{PhTx}$ and nimodipine (2), during baseline in current clamp (3), at 30 min after HFS (4), and during DCG-IV (5). Each circle represents a single EPSC or EPSP recorded at $0.2 \mathrm{~Hz}$. First break in timescale represents the switch from voltage clamp to current clamp. MF EPSCS were weakly $(<10 \%)$ sensitive to $\mathrm{PhTx}(5 \mu \mathrm{M})$ and LTP was blocked in the presence of nimodipine. The inset shows average traces (10 sweeps) from the same experiment at time indicated by the numbers. Calibration: $2 \mathrm{mV}, 25 \mathrm{~ms}$. C. Cumulative probability distribution of normalized EPSP slopes from all the cells treated with nimodipine before or after HFS. Each circle represents the magnitude of change relative to a normalized baseline computed from the average of the baseline EPSPs. The start of the horizontal arrow corresponds to the minimum criteria for LTP. ${ }^{*} p<0.05$ and ${ }^{* *} p<0.001$ or higher statistical significance. Error bars indicate SEM.

sion bath before the delivery of HFS. We found that nimodipine did not alter the properties of the evoked MF EPSPs (supplemental Table 1, available at www. jneurosci.org as supplemental material) but prevented LTP of the EPSP slope $(98.4 \pm 9 \%$ at $5 \mathrm{~min}, p>0.05 ; 106.7 \pm$ $10 \%$ at 30 min after HFS, $p>0.05 ; N=9$ ) (Fig. $7 A, C$ ). In three of these cells, we assessed the effect of nimodipine on the isolated CI-AMPAR component by including $\operatorname{PhTx}(5 \mu \mathrm{M})$ in the perfusion bath before HFS. In voltage-clamp conditions $\left(V_{\mathrm{h}}=\right.$ $-70 \mathrm{mV}$ ), PhTx moderately reduced MF EPSC amplitudes ( $91.2 \pm 4 \%$ of baseline; $p<0.001$, unpaired $t$ test) (Fig. 7B). At the end of the PhTx application, recording was switched to current-clamp conditions $(-70 \mathrm{mV})$ and HFS was delivered to the MF input. After the HFS, the isolated CIAMPAR component of the MF EPSP exhibited PTP $(154.8 \pm 6.5 \%$ of baseline $)$ but did not show LTP (110.8 $\pm 6 \%$ of control at 30 min after HFS; $p>0.5$, one-way ANOVA). Bath application of DCG-IV (1 $\mu \mathrm{M})$ confirmed that the EPSCs were generated by MF synapses $(66.1 \pm 4.4 \%$ inhibition) (Fig. $7 B$ ). We also examined the effect of L-type channel blockade on the maintenance of LTP by adding nimodipine $10 \mathrm{~min}$ after the delivery of the HFS. The results of these experiments indicated that nimodipine did not affect the potentiated MF EPSP slope $(169.6 \pm 10 \%$ at 30 min after HFS, $p<0.001 ; N=5$ ) (Fig. $7 A, C)$. In both cases, DCG-IV applied at the end of the experiments reduced the responses (59 \pm 5 and $60.3 \pm 2 \%$ with nimodipine before and after, respectively; $p<0.001$, one-way ANOVA) (Fig. 7A). Together, these findings show that the induction but not the maintenance of LTP at

some L-M interneurons loaded with $20 \mathrm{~mm}$ BAPTA may indicate that some accumulation of $\mathrm{Ca}^{2+}$ ions took place near the $\mathrm{Ca}^{2+}$ sensor that triggers LTP (see Discussion).

\section{MF LTP requires L-type $\mathrm{Ca}^{2+}$ channel activation}

On the basis of the findings described above, we hypothesized that the induction of MF LTP in L-M interneurons requires postsynaptic $\mathrm{Ca}^{2+}$ influx via voltage-gated channels. It has been shown that activation of the L-type $\mathrm{Ca}^{2+}$ channel is necessary for the induction of NMDAR-independent forms of LTP in the hippocampus (Grover and Teyler, 1992; Kullmann et al., 1992; Huang and Malenka, 1993; Chen et al., 1998; Kapur et al., 1998; Lauri et al., 2003) and amygdala (Weisskopf et al., 1999). These data are compatible with the observations that L-type channels are abundantly expressed on the proximal dendrites and soma of hippocampal pyramidal cells and interneurons (Ahlijanian et al., 1990; Westenbroek et al., 1990) and capable of producing considerable increases in cytosolic $\mathrm{Ca}^{2+}$ (Miyakawa et al., 1992; Denk et al., 1996). To test whether L-type channel activation is required for MF LTP induction in L-M interneurons, the L-type channel antagonist nimodipine $(10 \mu \mathrm{M})$ was added to the perfu-
MF synapses on L-M interneurons required the activation of L-type channels.

\section{Blockade of $\mathrm{mGluR} 1 \alpha, \mathrm{IP}_{3}$ receptors, or ryanodine receptors} results in MF LTD

The group I mGluRs (mGluR1/mGluR5) are expressed in the periphery of the postsynaptic densities in the s. lacunosum moleculare of area CA1 (Lujan et al., 1996). In particular, the mGluR $1 \alpha$ isoform is mainly located postsynaptically in GABAcontaining interneurons (Baude et al., 1993; Ferraguti et al., 2004) and is required for LTP induction in CA1 alveus/oriens interneurons (Lapointe et al., 2004; Topolnik et al., 2006). To investigate whether mGluR $1 \alpha$ activation is also involved in the induction of MF LTP in L-M interneurons, HFS was applied in the presence of the selective antagonist LY367385 (100 $\mu \mathrm{M})$. Although PTP was similar to baseline $(173 \pm 7 \%)$, the same HFS protocol that induces MF LTP in naive slices induced MF LTD in LY367385-treated slices $(73 \pm 12 \%$ at 30 min after HFS; $p<$ $0.001 ; N=11 ; 66.8 \pm 4.5 \%$ inhibition by DCG-IV; $p<0.001$, one-way ANOVA) (Fig. 8A). We also tested the effect of LY367385 on the isolated CI-AMPAR component by applying 
PhTx $(5 \mu \mathrm{M})$ to the perfusion bath before HFS. In voltage-clamp conditions $\left(V_{\mathrm{h}}=\right.$ $-70 \mathrm{mV}$ ), PhTx modestly reduced MF EPSC amplitudes $(95.4 \pm 3 \%$ of baseline; $p<0.05$, unpaired $t$ test) (Fig. $8 B$ ). At the end of the PhTx application, recordings were switched to current-clamp conditions $(-70 \mathrm{mV})$ before the delivery of HFS to MFs. After a robust PTP $(165.6 \pm 1 \%)$, MF EPSPs underwent a pronounced LTD $(71 \pm 3.6$ at 30 min after HFS; $p<0.001$; $N=3$ ) and were further inhibited by DCG-IV $(69.3 \pm 9.1 \%$ of control).

To determine the locus of LTD expression, we examined the percentage of failures and $\mathrm{CV}$ using a minimal stimulation protocol. In the presence of LY367385, HFS paired with a postsynaptic depolarization pulse $(\sim 33 \mathrm{pA})$ resulted in a depression of MF EPSP amplitudes (0.55 \pm $0.09 \mathrm{mV}$ in baseline; $0.41 \pm 0.06 \mathrm{mV}$ at 25-30 min after HFS; $p<0.05$, one-way ANOVA; $N=5$ ) (supplemental Fig. $3 A, B$, available at www.jneurosci.org as supplemental material). The EPSP depression was associated with an increase in the failure rate $(35-65 \%$ during baseline; $60-80 \%$ at $25-30 \mathrm{~min}$ after HFS; $p<$ 0.001, one-way ANOVA) (supplemental Fig. 3C, available at www.jneurosci.org as supplemental material) and increase in the CV (0.6 \pm 0.08 during baseline, $0.89 \pm$ 0.08 at $25-30 \mathrm{~min}$ after HFS; $p<0.001$, one-way ANOVA; $N=5$ ) (supplemental Fig. $1 D$, available at www.jneurosci.org as supplemental material). After $30 \mathrm{~min}$ of LTD, the application of DCG-IV $(1 \mu \mathrm{M})$ decreased EPSP amplitude to $0.33 \pm 0.02$ $\mathrm{mV}(p<0.01 ; N=4)$ (supplemental Fig. $3 A, B$, available at www.jneurosci.org as supplemental material) and increased the failure rate by $55-90 \%$ ( $p<0.001$, oneway ANOVA) (supplemental Fig. 3C,D, available at www. jneurosci.org as supplemental material). These data indicate that MF LTD, like MF LTP, is presynaptically expressed. In contrast to the marked effects on synaptic plasticity mediated by the mGluR $1 \alpha$, application of the mGluR5-selective antagonist MPEP $(25 \mu \mathrm{M})$ did not affect the polarity of synaptic plasticity induced by MF HFS (172 $\pm 16 \%$ at 30 min after HFS; $p<0.001$, one-way ANOVA; $N=10$; DCG-IV sensitivity, $64.5 \pm 3 \%$ of baseline; $p<0.05$ ) (supplementalFig.4, availableatwww.jneurosci. org as supplemental material).

Activation of mGluR1 $\alpha$ is known to increase L-type $\mathrm{Ca}^{2+}$ channel conductance and $\mathrm{Ca}^{2+}$ release from intracellular stores in the endoplasmic reticulum (ER) (Chavis et al., 1996; Woodhall et al., 1999; Fagni et al., 2000; Ouardouz et al., 2003; Bardo et al., 2006) via stimulation of the inositol $(1,4,5)$-trisphosphate receptor $\left(\mathrm{IP}_{3} \mathrm{R}\right)$. To test the involvement of the $\mathrm{IP}_{3}-\mathrm{IP}_{3} \mathrm{R}$ cascade initiated during the induction of MF LTP, we loaded the cells with heparin $(4 \mathrm{mg} / \mathrm{ml})$, an antagonist of $\mathrm{IP}_{3} \mathrm{Rs}$ (Taylor and Broad, 1998). The dialysis with heparin did not affect PTP (155.9 \pm $8.3 \%$ ) but resulted in MF LTD (76.9 $\pm 5.7 \%$ at 30 min after HFS;
$N=8 ; p<0.001$, one-way ANOVA; $76.1 \pm 4.7 \%$ inhibition by DCG-IV; $p<0.001$, one-way ANOVA) (Fig. 9A-C).

The rise in $\left[\mathrm{Ca}^{2+}\right]_{\mathrm{i}}$ caused by activation of $\mathrm{L}$-type channel and $\mathrm{IP}_{3}$ receptors could result in $\mathrm{Ca}^{2+}$-induced $\mathrm{Ca}^{2+}$ release (CICR) from the ER via activation of the ryanodine receptor (RyR) (Wang et al., 1996; Balschun et al., 1999; Nakamura et al., 2000; Lu and Hawkins, 2002; Raymond and Redman, 2002; Morikawa et al., 2003; Sokolov et al., 2003; Tozzi et al., 2003; Lapointe et al., 2004; Mellentin et al. 2007). In dentate gyrus and CA3 hippocampal cells, RyR levels are higher than $\mathrm{IP}_{3} \mathrm{R}$ levels (Bardo et al., 2006). Furthermore, a recent study has shown that the distribution of RyR isotype 3 immunoreactivity is strong in the s. lacunosum-moleculare (Hertle and Yeckel, 2007). To examine whether blockade of the RyR also may induce LTD, ryanodine was included in the whole-cell pipette $(10 \mu \mathrm{M} ; N=4$; or $100 \mu \mathrm{M}$; $N=4)$. Because both concentrations produced the same effect, the data were pooled for statistical analysis. After PTP (176 \pm $15 \%)$, MF EPSP slopes decayed to a stable LTD (75 $\pm 4.3 \%$ at 30 min after HFS; $N=8 ; p<0.001 ; 75.2 \pm 2.4 \%$ inhibition by DCG-IV; $p<0.001$, one-way ANOVA) (Fig. $9 A-C$ ). Together, these results would suggest that the dynamic regulation of 

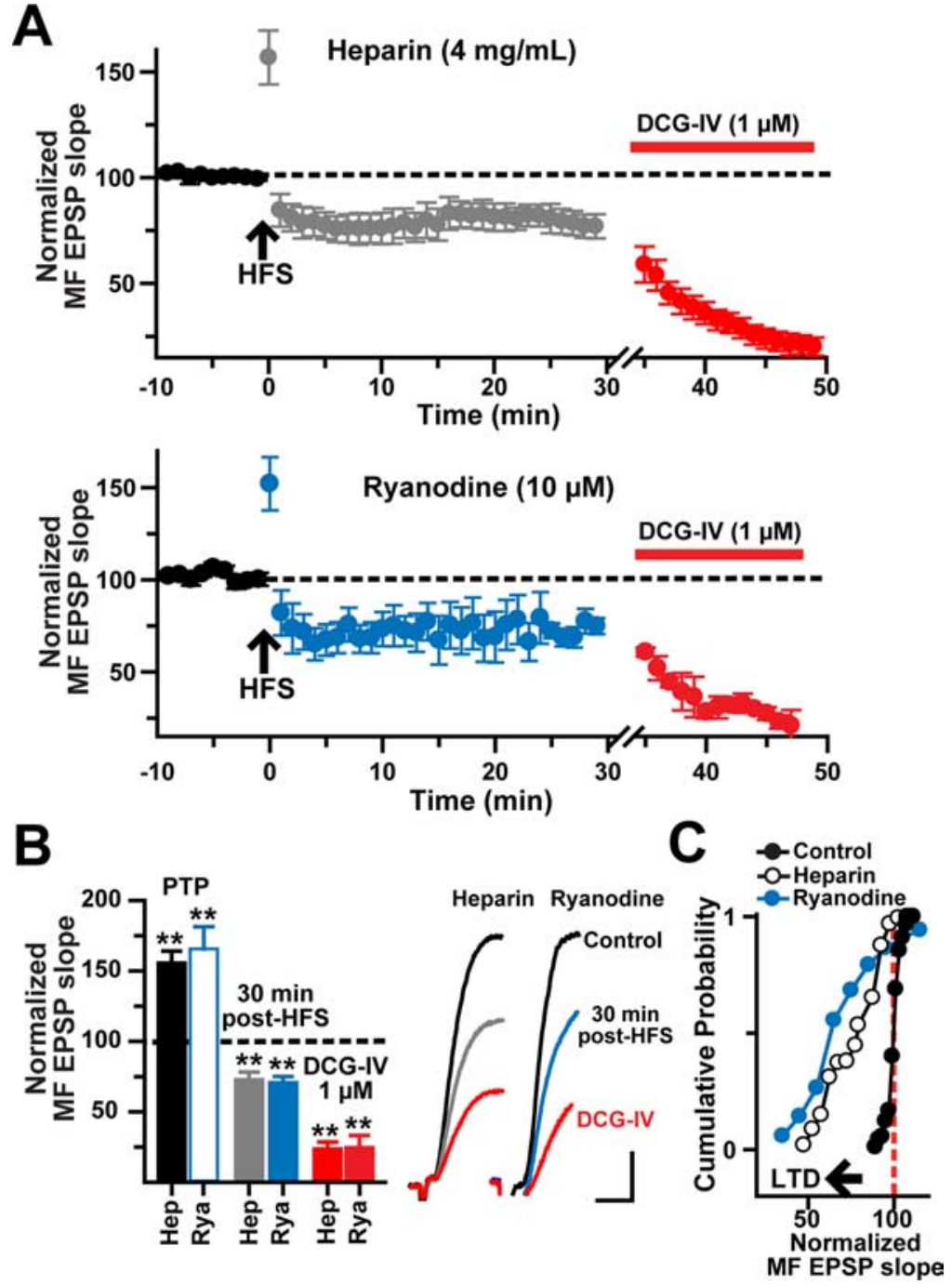

Figure 9. Induction of MF LTP requires $\mathrm{Ca}^{2+}$ release from intracellular stores. $A$, Time course of normalized MF EPSP slopes before and after HFS from heparin- (top graph; $N=8$ ) and ryanodine- (bottom graph; $N=8$ ) loaded cells showing PTP but not LTP. The DCG-IV sensitivity confirmed the MF origin of EPSPs. B, Bar chart summarizing the post-HFS effect of postsynaptic loading with heparin or ryanodine. The insets are average MF EPSP slopes (10 consecutive sweeps) from a representative cell loaded with heparin or ryanodine. Calibration: $2 \mathrm{mV}, 5 \mathrm{~ms}$. C, Cumulative probability distribution of normalized EPSP slopes before and during LTD (measured after the first 5 min after HFS to exclude PTP) for the same cells. Each point represents the magnitude of change relative to a normalized baseline computed from the average EPSP slope in heparin- or ryanodine-loaded cells. The start of the horizontal arrow corresponds to the minimum criteria for LTD (depression of the synaptic transmission $\leq 25 \%$ below baseline for $30 \mathrm{~min}) .{ }^{* *} p<0.001$ or higher statistical significance. Error bars indicate SEM.

$\left[\mathrm{Ca}^{2+}\right]_{\mathrm{i}}$ by the interaction between $\mathrm{IP}_{3} \mathrm{R}$ and RyR (Nash et al., 2002) determines the balance between MF LTP and LTD (see Fig. 11).

MF LTD induced by blockade of mGluR $1 \alpha$ requires $\mathrm{Ca}^{2+}$ influx through L-type channel

The lack of long-term changes at MF synapses in the presence of nimodipine (Fig. 7) suggests that LTD, like LTP, also depends on $\mathrm{Ca}^{2+}$ influx through the L-type channel. In the hippocampus, NMDAR-independent forms of LTD have been shown to be dependent on L-type $\mathrm{Ca}^{2+}$ activation (Christie and Abraham, 1994; Christie et al., 1997; Wang et al., 1997). We hypothesized that, in the absence of the mGluR $1 \alpha$ signal transduction cascade, the source for $\left[\mathrm{Ca}^{2+}\right]_{\mathrm{i}}$ increase responsible for LTD is through the L-type channels. Indeed, we found that HFS applied in the presence of LY367385 $(100 \mu \mathrm{M})$ and nimodipine $(10 \mu \mathrm{M})$ did not change the MF
EPSP slope ( $92 \pm 7.3 \%$ of control at 30 min after HFS; $N=10 ; p>0.216$, paired $t$ test) (Fig. 10). After $30 \mathrm{~min}$ after HFS, DCG-IV reduced the EPSP slope by $68.5 \pm 7.4 \%$ of control ( $p<0.0001$, unpaired $t$ test).

\section{Discussion}

Previous reports have established that LTD mediated by CP-AMPAR or NMDAR is the preferential form of longterm plasticity at MF synapses on stratum lucidum interneurons (Maccaferri et al., 1998; Tóth and McBain, 1998; Tóth et al., 2000; Lei and McBain, 2002). Here, we demonstrate that the majority of L-M interneurons (78\%) recorded near the SDG exhibit robust PTP and input-specific NMDAR-independent LTP at predominantly CI-AMPAR MF synapses. These observations support the notion that the induction of pathway-specific LTP does not require dendritic spines (Lamsa et al., 2005). In contrast, in the majority of PhTx-sensitive MF synapses, the isolated CI-AMPAR component showed a reduced PTP and were unaffected by HFS. Only in few of the CP-AMPAR synapses, the CIAMPAR-mediated EPSP exhibited a lack of PTP followed by LTD. Given that the AMPAR sensitivity to PhTx was not assessed in every experiment, the generality of our conclusion that only synapses predominantly containing CI-AMPARs are able to undergo MF LTP remains to be determined.

The axons of L-M interneurons branch in strata lacunosum-moleculare, radiatum, and pyramidale, and make direct symmetrical synaptic contacts with pyramidal cells (Kunkel et al., 1988) that provide feedforward inhibition to pyramidal cells (Lacaille and Schwartzkroin, 1988; Williams et al., 1994; Vida et al., 1998). Therefore, our results are consistent with the claim that LTP occurs at excitatory inputs to GABAergic interneurons inhibiting principal cells in a feedforward manner (Kullmann and Lamsa, 2007). We also found that MF synapses on L-M interneurons are bidirectionally modifiable. LTP induction required the joint activation of L-type $\mathrm{Ca}^{2+}$ channels and mGluR1 $\alpha$ receptors. During blockade of mGluR $1 \alpha$, the same stimulation protocol that induces MF LTP in naive slices induced MF LTD. The requirement for conjunctive presynaptic and postsynaptic activity to induce both LTP and LTD fulfills the condition for Hebbian forms of synaptic plasticity.

To ensure that MF LTP in L-M interneurons is not attributable to the induction of NMDAR-independent LTP at polysynaptic recurrent synapses from intercalated pyramidal cells, we first systematically identified MF EPSPs based on their differential sensitivity to DCG-IV. Second, we explicitly tested the lack of C/A LTP by applying HFS to C/A fibers in the absence of NMDAR activation. Third, LTP was detected with a minimal 

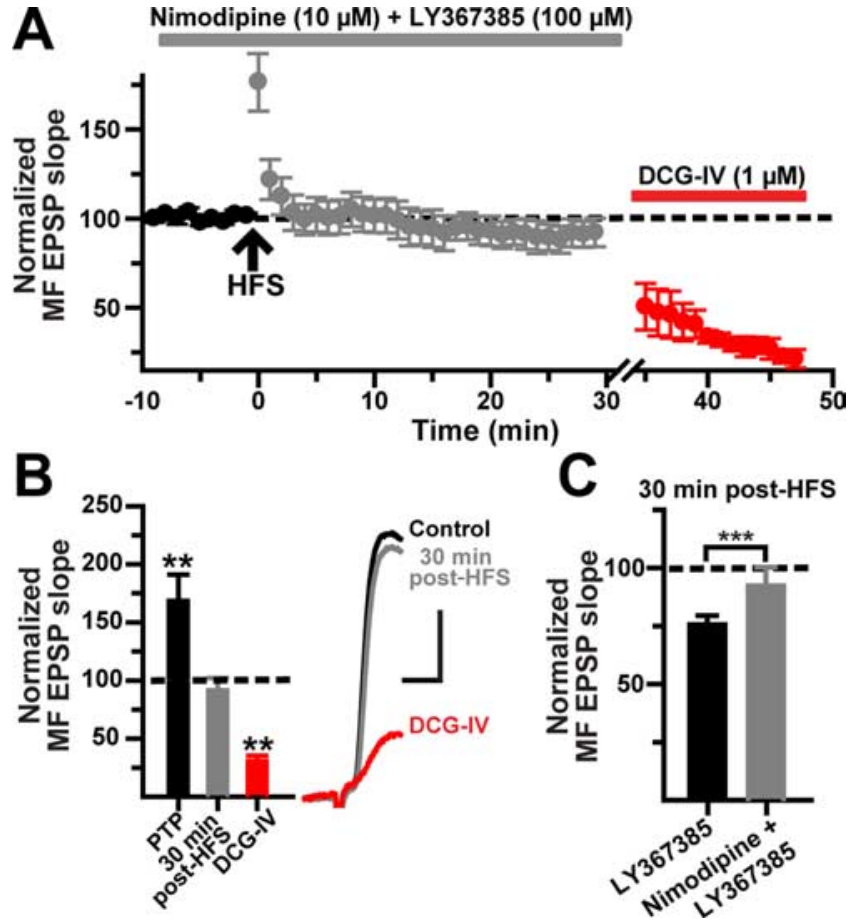

Figure 10. MF LTD requires L-type $\mathrm{Ca}^{2+}$ channel activation. $\boldsymbol{A}$, Time course of normalized MFEPSP slopes $(N=10)$ showing that nimodipine added before the HFS prevents the induction of LTD induced in the presence of the mGluR1 $\alpha$ antagonist LY367385 (100 $\mu \mathrm{M}$ ). B, Summary bar graph for the same cells showing the post-HFS effect of nimodipine plus LY367385 applications and the subsequent reduction by DCG-IV. The inset shows average MF EPSP slopes (10 consecutive sweeps) from one representative experiment. Calibration: $2 \mathrm{mV}, 5 \mathrm{~ms}$. C, Population data showing $30 \mathrm{~min}$ after HFS changes in EPSP slope in the presence of LY367385 versus LY367385 plus nimodipine. ${ }^{* * *} p<0.00002$ or higher statistical significance. Error bars indicate SEM.

stimulation protocol during which only one or a few synapses were activated (Stevens and Wang, 1994; Xiang et al., 1994; Perez et al., 2001). Finally, LTP was prevented with somatic voltage clamping during HFS and by intracellular injections of the $\mathrm{Ca}^{2+}$ chelator BAPTA. Together, these data clearly show that MF LTP was induced postsynaptically and expressed directly at MF synapses on L-M interneurons.

MF synapses onto interneurons are made either by small en passant varicosities originating from the axon trunks of MFs traveling in the s. lucidum of CA3 or from dentate gyrus hilar collaterals or filipodial extensions from the large synaptic boutons innervating the pyramidal cells (Claiborne et al., 1986; Acsády et al., 1998; Bischofberger and Jonas, 2002). In contrast, MF synapses on pyramidal cells have large presynaptic boutons with small finger-like extensions (Hamlyn, 1962; Amaral, 1979). Despite significant morphological differences in presynaptic terminals, MF synapses on pyramidal cells and the subpopulation of L-M interneurons containing MF CI-AMPARs share some similarities in the mechanisms of synaptic transmission and use-dependent plasticity. Pyramidal cells, which are predominantly innervated by MFs at CI-AMPAR-containing synapses (Tóth et al., 2000), exhibit robust PTP and LTP, and LTP is induced postsynaptically (Jaffe and Johnston, 1990; Yeckel et al., 1999; Contractor et al., 2002; Sokolov et al. 2003) (but see Zalutsky and Nicoll, 1990). However, the PTP and LTP reported here are comparatively smaller than the PTP and LTP at MF synapses made by the axon collaterals of granule cells on basket cells in the dentate gyrus (Alle et al., 2001). However, MF LTP in these interneurons was only partially attenuated by BAPTA, indicating that the induction mechanisms are more resilient to chelation of postsynaptic $\mathrm{Ca}^{2+}$ than those underlying LTP induction in L-M interneurons.

Both LTP and LTD were prevented by nimopidine applications before HFS. An essential role of L-type channels in longterm synaptic plasticity in CA3 interneurons has not previously been demonstrated. Our results also indicate that mGluR $1 \alpha$ serves as a molecular switch that changes the outcome of the synaptic modification triggered by activation of L-type $\mathrm{Ca}^{2+}$ channels (Fig. 11). Activation of this switch by glutamate release results in LTP induction; however, if the switch is inoperative LTD is triggered by the $\mathrm{Ca}^{2+}$ influx through activation of the L-type channel after the postsynaptic depolarization mediated by CI-AMPA receptor activation (Fig. 11). These findings would be consistent with the idea that the magnitude of the activitydependent rise in postsynaptic $\mathrm{Ca}^{2+}$ is a major determinant of the direction of change in synaptic efficacy (Bear et al., 1987; Artola and Singer, 1993; Hansel et al., 1997; Cormier et al., 2001). Experimental observations suggest that the induction threshold for LTP requires higher levels of postsynaptic $\left[\mathrm{Ca}^{2+}\right]_{i}$ than for LTD (Cummings et al., 1996; Cho et al., 2001; Nevian and Sakmann, 2006). Therefore, LTP at MF synapses onto L-M interneurons may only be induced after an increase in the L-type channel conductance (Chavis et al., 1996) supplemented by $\mathrm{Ca}^{2+}$ mobilization via $\mathrm{IP}_{3} \mathrm{R}$, and RyR-mediated CICR (Nakamura et al., 2000) (Fig. 11). However, LTP may not depend solely on global $\left[\mathrm{Ca}^{2+}\right]_{\mathrm{i}}$ but on a separate $\mathrm{Ca}^{2+}$ sensor (Karmarkar and Buonomano, 2002; Bender et al., 2006; Nevian and Sakmann, 2006), enabled by $\mathrm{mGluR} 1 \alpha$ activation. Another obligatory step in the downstream signaling cascade leading to MF LTP may involve the activation of PKA (protein kinase A) and PKC (E. J. Galván and G. Barrionuevo, unpublished observations). In turn, PKC activation could mediate a phosphorylation-triggered desensitization of mGluR $1 \alpha$ (Dale et al., 2002; Sato et al., 2004) perhaps via coactivation of mGluR5 (Poisik et al., 2003), which would prime potentiated MF synapses for a subsequent induction of LTD. Such metaplasticity (Abraham and Bear, 1996) could provide with a homeostatic mechanism to reset synaptic weights and prevent synaptic saturation (Turrigiano and Nelson, 2004) at MF synapses on L-M interneurons.

Previous reports have demonstrated that MF synapses on lucidum interneurons and dentate gyrus basket cells are able to undergo bidirectional plasticity. However, the mechanism that regulates the polarity of synaptic efficacy in these interneuron populations is different from that reported here. In lucidum interneurons in which MF LTD at naive synapses requires presynaptically located mGluR7 activation, HFS elicited MF LTP/dedepression only after L-AP4 applications induced chemical LTD and internalization of mGluR7 localized at MF terminals (Pelkey et al., 2005). The requirement for strong presynaptic receptor activation to elicit LTP indicates that this synaptic plasticity is more suitable for maintaining network stability during sustained activation of granule cells (e.g., during epileptic bursting) (Pelkey et al., 2005). In dentate gyrus basket cells, MF synapses can exhibit either LTP or LTD depending on the postsynaptic membrane potential during HFS (Alle et al., 2001).

Although many mechanisms for NMDAR-independent LTP/ LTD have been described in hippocampal interneurons, the expression of this plasticity appears solely determined by changes in transmitter release probability (Kullmann and Lamsa, 2007). Indeed, the changes in PPR, coefficient of variation, and failure rate that were detected during MF LTP/LTD are all indicative of a presynaptic locus of expression for the changes in synaptic effi- 


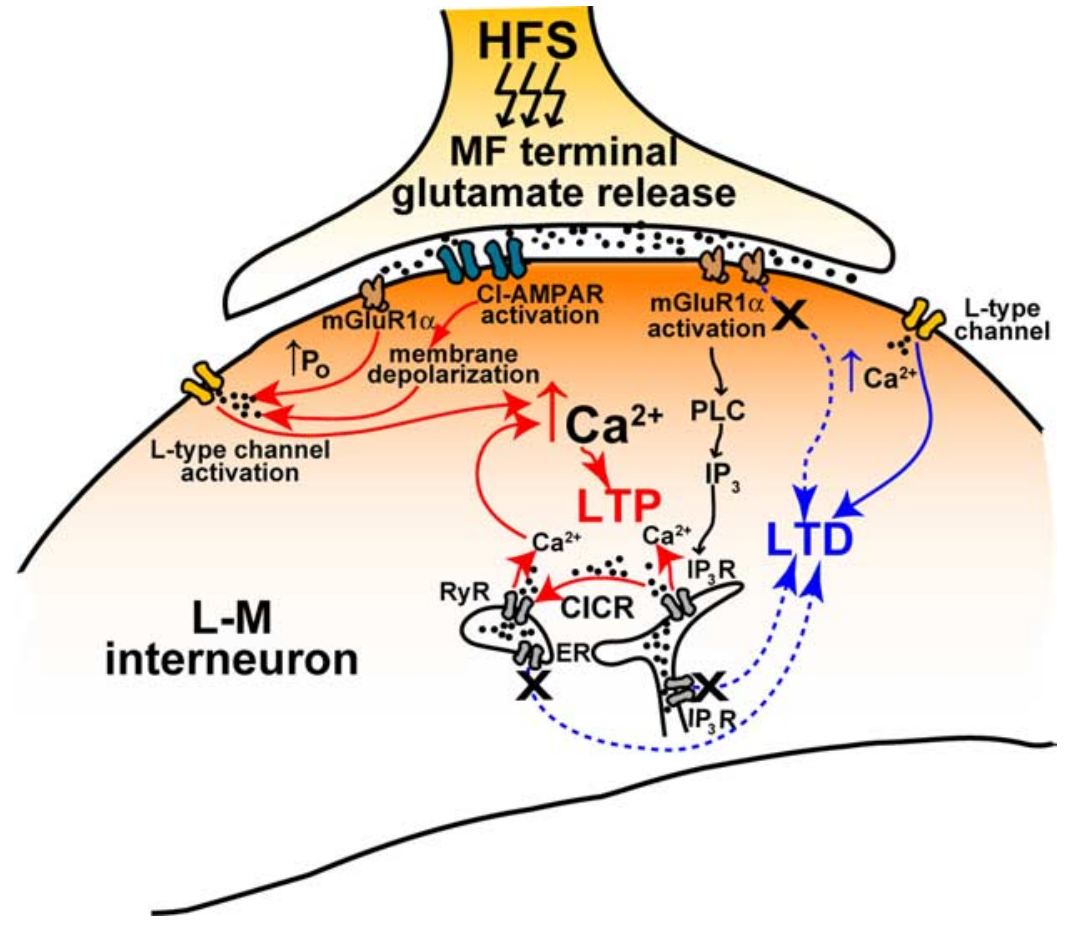

Figure 11. Schematic representation of the mechanisms for induction of bidirectional plasticity at MF synapses onto spineless dendrites of L-M interneurons. MF LTP has a stronger calcium dependency than MF LTD and requires the initial activation of two sources of calcium: (1) from the extracellular space via L-type $\mathrm{Ca}^{2+}$ channels and (2) from the ER via mGluR1 $\alpha$-dependent phospholipase C(PLC) pathway to promote $\mathrm{IP}_{3}$-mediated $\mathrm{Ca}^{2+}$ mobilization. Enhancement of the L-type channel conductance by mGluR1 $\alpha$ activation produces additional increase in $\left[\mathrm{Ca}^{2+}\right]_{\mathrm{i}}$. Calcium signals from these two sources trigger CICR from RyRoperated $\mathrm{Ca}^{2+}$ stores. The RyR-mediated component of the intracellular $\mathrm{Ca}^{2+}$ signal amplifies $\mathrm{Ca}^{2+}$ liberated through $\mathrm{IP}_{3} \mathrm{R}$. In contrast, $\mathrm{Ca}^{2+}$ influx via L-type channels is sufficient to induce LTD in the absence of mGluR1 $\alpha$ activation. the same stimulation protocol that induces MF LTP in pyramidal cells (cf. Henze et al., 2000; Nicoll and Schmitz, 2005). Similar strengthening of MF connections on both postsynaptic targets by the same presynaptic activity could contribute to preserve the focus of the excitatory drive from the dentate gyrus to the CA3 neuronal network. This would presumably be important for invoking a distributed encoding that minimizes the overlap between incoming cortical patterns that underlie different memory representations.

\section{References}

Abraham WC, Bear MF (1996) Metaplasticity: the plasticity of synaptic plasticity. Trends Neurosci 19:126-130.

Acsády L, Kamondi A, Sík A, Freund T, Buzsáki G (1998) GABAergic cells are the major postsynaptic targets of mossy fibers in the rat hippocampus. J Neurosci 18:3386-3403.

Ahlijanian MK, Westenbroek RE, Catterall WA (1990) Subunit structure and localization of dihydropyridine-sensitive calcium channels in mammalian brain, spinal cord, and retina. Neuron 4:819-832.

Alle H, Jonas P, Geiger JR (2001) PTP and LTP at a hippocampal mossy fiber-interneuron synapse. Proc Natl Acad Sci U S A 98:14708-14713.

Amaral DG (1979) Synaptic extensions from the mossy fibers of the fascia dentata. Anat Embryol (Berl) 155:241-251.

Artola A, Singer W (1993) Long-term depression cacy. Presynaptic changes at MF synapses on pyramidal cells and interneurons have been previously reported during both LTP (Staubli et al., 1990; Zalutsky and Nicoll, 1990; Xiang et al., 1994; Alle et al., 2001) and LTD (Domenici et al., 1998; Lei and McBain, 2002). We speculate that the postsynaptic events in response to HFS are expressed presynaptically by a retrograde signaling messenger.

According to computational and behavioral studies on hippocampal function (McNaughton and Morris, 1987; Treves and Rolls, 1992; O’Reilly and McClelland, 1994; Lisman, 1999; Leutgeb et al., 2007), the strong and sparse input from the MF input selects nonoverlapping subpopulations of pyramidal cells to encode new memory representations in a way that reduces interference between stored information. Feedforward inhibitory interneurons also may play a role in regulating the transfer and decorrelation of the compressed memory representation in area CA3. For example, the parallel activation of feedforward inhibitory interneurons by MFs could contribute to pattern separation by restricting the temporal window for synaptic integration and action potential firing in pyramidal cells (Pouille and Scanziani, 2001; Perez-Orive et al., 2002). Therefore, the fine "tuning" of the pyramidal cell network during pattern separation requires a functional balance between monosynaptic excitation and disynaptic inhibition (Mariño et al., 2005). If MF LTP were confined to synapses on pyramidal cells alone, this could limit the sparseness of the memory representation unless it is accompanied by a compensatory LTP on feedforward inhibitory interneurons (Lamsa et al., 2005). The present results demonstrate that the feedforward inhibitory drive to CA3 mediated by the MF input to L-M interneurons has the ability to undergo Hebbian LTP in response to of excitatory synaptic transmission and its relationship to long-term potentiation. Trends Neurosci 16:480-487.

Balschun D, Manahan-Vaughan D, Wagner T, Behnisch T, Reymann KG, Wetzel W (1999) A specific role for group I mGluRs in hippocampal LTP and hippocampus-dependent spatial learning. Learn Mem 6:138-152.

Bardo S, Cavazzini MF, Emptage N (2006) The role of the endoplasmic 27:78-84.

Baude A, Nusser Z, Roberts JD, Mulvihill E, McIlhinney RA, Somogyi P (1993) The metabotropic glutamate receptor (mGluR1 alpha) is concentrated at perisynaptic membrane of neuronal subpopulations as detected by immunogold reaction. Neuron 11:771-787.

Bear MF, Cooper LN, Ebner FF (1987) A physiological basis for a theory of synapse modification. Science 237:42-48.

Bender VA, Bender KJ, Brasier DJ, Feldman DE (2006) Two coincidence detectors for spike timing-dependent plasticity in somatosensory cortex. J Neurosci 26:4166-4177.

Bischofberger J, Jonas P (2002) TwoB or not twoB: differential transmission at glutamatergic mossy fiber-interneuron synapses in the hippocampus. Trends Neurosci 25:600-603.

Calixto E, Galvan EJ, Card JP, Barrionuevo G (2008) Coincidence detection of convergent perforant path and mossy fibre inputs by CA3 interneurons. J Physiol 586:2695-2712.

Chavis P, Fagni L, Lansman JB, Bockaert J (1996) Functional coupling between ryanodine receptors and L-type calcium channels in neurons. Nature 382:719-722.

Chen HX, Hanse E, Pananceau M, Gustafsson B (1998) Distinct expressions for synaptic potentiation induced by calcium through voltage-gated calcium and $\mathrm{N}$-methyl-D-aspartate receptor channels in the hippocampal CA1 region. Neuroscience 86:415-422.

Cho K, Aggleton JP, Brown MW, Bashir ZI (2001) An experimental test of the role of postsynaptic calcium levels in determining synaptic strength using perirhinal cortex of rat. J Physiol 532:459-466.

Christie BR, Abraham WC (1994) L-Type voltage-sensitive calcium channel reticulum $\mathrm{Ca}^{2+}$ store in the plasticity of central neurons. Trends Neurosci 
antagonists block heterosynaptic long-term depression in the dentate gyrus of anaesthetized rats. Neurosci Lett 167:41-45.

Christie BR, Schexnayder LK, Johnston D (1997) Contribution of voltagegated $\mathrm{Ca}^{2+}$ channels to homosynaptic long-term depression in the CA1 region in vitro. J Neurophysiol 77:1651-1655.

Claiborne BJ, Amaral DG, Cowan WM (1986) A light and electron microscopic analysis of the mossy fibers of the rat dentate gyrus. J Comp Neurol 246:435-458.

Contractor A, Rogers C, Maron C, Henkemeyer M, Swanson GT, Heinemann SF (2002) Trans-synaptic Eph receptor-ephrin signaling in hippocampal mossy fiber LTP. Science 296:1864-1869.

Cormier RJ, Greenwood AC, Connor JA (2001) Bidirectional synaptic plasticity correlated with the magnitude of dendritic calcium transients above a threshold. J Neurophysiol 85:399-406.

Cummings JA, Mulkey RM, Nicoll RA, Malenka RC (1996) $\mathrm{Ca}^{2+}$ signaling requirements for long-term depression in the hippocampus. Neuron 16:825-833.

Dale LB, Babwah AV, Ferguson SSG (2002) Mechanisms of metabotropic glutamate receptor desensitization: role in the patterning of effector enzyme activation. Neurochem Int 41:319-326.

Denk W, Yuste R, Svoboda K, Tank DW (1996) Imaging calcium dynamics in dendritic spines. Curr Opin Neurobiol 6:372-378.

Dingledine R, Borges K, Bowie D, Traynelis SF (1999) The glutamate receptor ion channels. Pharmacol Rev 51:7-61.

Domenici MR, Berretta N, Cherubini E (1998) Two distinct forms of longterm depression coexist at the mossy fiber-CA3 synapse in the hippocampus during development. Proc Natl Acad Sci U S A 95:8310-8315.

Fagni L, Chavis P, Ango F, Bockaert J (2000) Complex interactions between mGluRs, intracellular $\mathrm{Ca}^{2+}$ stores and ion channels in neurons. Trends Neurosci 23:80-88.

Ferraguti F, Cobden P, Pollard M, Cope D, Shigemoto R, Watanabe M, Somogyi P (2004) Immunolocalization of metabotropic glutamate receptor 1alpha (mGluR1alpha) in distinct classes of interneuron in the CA1 region of the rat hippocampus. Hippocampus 14:193-215.

Freund TF, Buzsáki G (1996) Interneurons of the hippocampus. Hippocampus 6:347-470.

Grover LM, Teyler TJ (1992) N-Methyl-D-aspartate receptor-independent long-term potentiation in area CA1 of rat hippocampus: input-specific induction and preclusion in a non-tetanized pathway. Neuroscience 49:7-11.

Hamlyn LH (1962) The fine structure of the mossy fibre endings in the hippocampus of the rabbit. J Anat 96:112-120.

Hansel C, Artola A, Singer W (1997) Relation between dendritic Ca ${ }^{2+}$ levels and the polarity of synaptic long-term modifications in rat visual cortex neurons. Eur J Neurosci 9:2309-2322.

Harris EW, Cotman CW (1986) Long-term potentiation of guinea pig mossy fiber responses is not blocked by $N$-methyl-D-aspartate antagonists. Neurosci Lett 70:132-137.

Henze DA, Urban NN, Barrionuevo G (2000) The multifarious hippocampal mossy fiber pathway: a review. Neuroscience 98:407-427.

Henze DA, Wittner L, Buzsáki G (2002) Single granule cells reliably discharge targets in the hippocampal CA3 network in vivo. Nat Neurosci 5:790-795.

Hertle DN, Yeckel MF (2007) Distribution of inositol-1,4,5-trisphosphate receptor isotypes and ryanodine receptor isotypes during maturation of the rat hippocampus. Neuroscience 150:625-638.

Huang YY, Malenka RC (1993) Examination of TEA-induced synaptic enhancement in area CA1 of the hippocampus: the role of voltage-dependent $\mathrm{Ca}^{2+}$ channels in the induction of LTP. J Neurosci 13:568-576.

Jaffe D, Johnston D (1990) Induction of long-term potentiation at hippocampal mossy-fiber synapses follows a Hebbian rule. J Neurophysiol 64:948-960.

Kamiya H, Shinozaki H, Yamamoto C (1996) Activation of metabotropic glutamate receptor type $2 / 3$ suppresses transmission at rat hippocampal mossy fibre synapses. J Physiol 493:447-455.

Kapur A, Yeckel MF, Gray R, Johnston D (1998) L-Type calcium channels are required for one form of hippocampal mossy fiber LTP. J Neurophysiol 79:2181-2190.

Karmarkar UR, Buonomano DV (2002) A model of spike-timing dependent plasticity: one or two coincidence detectors? J Neurophysiol 88:507-513.

Kullmann DM, Lamsa KP (2007) Long-term synaptic plasticity in hippocampal interneurons. Nat Rev Neurosci 8:687-699.
Kullmann DM, Perkel DJ, Manabe T, Nicoll RA (1992) $\mathrm{Ca}^{2+}$ entry via postsynaptic voltage-sensitive $\mathrm{Ca}^{2+}$ channels can transiently potentiate excitatory synaptic transmission in the hippocampus. Neuron 9:1175-1183.

Kunkel DD, Lacaille JC, Schwartzkroin PA (1988) Ultrastructure of stratum lacunosum-moleculare interneurons of hippocampal CA1 region. Synapse 2:382-394.

Lacaille JC, Schwartzkroin PA (1988) Intracellular responses of rat hippocampal granule cells in vitro to discrete applications of norepinephrine. Neurosci Lett 89:176-181.

Laezza F, Doherty JJ, Dingledine R (1999) Long-term depression in hippocampal interneurons: joint requirement for pre- and postsynaptic events. Science 285:1411-1414.

Lamsa K, Heeroma JH, Kullmann DM (2005) Hebbian LTP in feed-forward inhibitory interneurons and the temporal fidelity of input discrimination. Nat Neurosci 8:916-924.

Lapointe V, Morin F, Ratte S, Croce A, Conquet F, Lacaille JC (2004) Synapsespecific mGluR1-dependent long-term potentiation in interneurones regulates mouse hippocampal inhibition. J Physiol 555:125-135.

Lauri SE, Bortolotto ZA, Nistico R, Bleakman D, Ornstein PL, Lodge D, Isaac JT, Collingridge GL (2003) A role for $\mathrm{Ca}^{2+}$ stores in kainate receptordependent synaptic facilitation and LTP at mossy fiber synapses in the hippocampus. Neuron 39:327-341.

Lawrence JJ, McBain CJ (2003) Interneuron diversity series: containing the detonation-feedforward inhibition in the CA3 hippocampus. Trends Neurosci 26:631-640.

Lawrence JJ, Grinspan ZM, McBain CJ (2004) Quantal transmission at mossy fibre targets in the CA3 region of the rat hippocampus. J Physiol 554:175-193.

Lei S, McBain CJ (2002) Distinct NMDA receptors provide differential modes of transmission at mossy fiber-interneuron synapses. Neuron 33:921-933.

Leutgeb JK, Leutgeb S, Moser MB, Moser EI (2007) Pattern separation in the dentate gyrus and CA3 of the hippocampus. Science 315:961-966.

Leutgeb S, Leutgeb JK (2007) Pattern separation, pattern completion, and new neuronal codes within a continuous CA3 map. Learn Mem 14:745-757.

Lisman JE (1999) Relating hippocampal circuitry to function: recall of memory sequences by reciprocal dentate-CA3 interactions. Neuron 22:233-242.

Lu YF, Hawkins RD (2002) Ryanodine receptors contribute to cGMPinduced late-phase LTP and CREB phosphorylation in the hippocampus. J Neurophysiol 88:1270-1278.

Lujan R, Nusser Z, Roberts JD, Shigemoto R, Somogyi P (1996) Perisynaptic location of metabotropic glutamate receptors mGluR1 and mGluR5 on dendrites and dendritic spines in the rat hippocampus. Eur J Neurosci 8:1488-1500

Maccaferri G, Tóth K, McBain CJ (1998) Target-specific expression of presynaptic mossy fiber plasticity. Science 279:1368-1370.

Mariño J, Schummers J, Lyon DC, Schwabe L, Beck O, Wiesing P, Obermayer K, Sur M (2005) Invariant computations in local cortical networks with balanced excitation and inhibition. Nat Neurosci 8:194-201.

McNaughton N, Morris RG (1987) Chlordiazepoxide, an anxiolytic benzodiazepine, impairs place navigation in rats. Behav Brain Res 24:39-46.

Mellentin C, Jahnsen H, Abraham WC (2007) Priming of long-term potentiation mediated by ryanodine receptor activation in rat hippocampal slices. Neuropharmacology 52:118-125.

Miyakawa H, Ross WN, Jaffe D, Callaway JC, Lasser-Ross N, Lisman JE, Johnston D (1992) Synaptically activated increases in $\mathrm{Ca}^{2+}$ concentration in hippocampal CA1 pyramidal cells are primarily due to voltagegated $\mathrm{Ca}^{2+}$ channels. Neuron 9:1163-1173.

Mori M, Gähwiler BH, Gerber U (2007) Recruitment of an inhibitory hippocampal network after bursting in a single granule cell. Proc Natl Acad Sci U S A 104:7640-7645.

Morikawa H, Khodakhah K, Williams JT (2003) Two intracellular pathways mediate metabotropic glutamate receptor-induced $\mathrm{Ca}^{2+}$ mobilization in dopamine neurons. J Neurosci 23:149-157.

Nakamura T, Nakamura K, Lasser-Ross N, Barbara JG, Sandler VM, Ross WN (2000) Inositol 1,4,5-trisphosphate $\left(\mathrm{IP}_{3}\right)$-mediated $\mathrm{Ca}^{2+}$ release evoked by metabotropic agonists and backpropagating action potentials in hippocampal CA1 pyramidal neurons. J Neurosci 20:8365-8376.

Nakazawa K, Quirk MC, Chitwood RA, Watanabe M, Yeckel MF, Sun LD, Kato A, Carr CA, Johnston D, Wilson MA, Tonegawa S (2002) Require- 
ment for hippocampal CA3 NMDA receptors in associative memory recall. Science 297:211-218.

Nash MS, Schell MJ, Atkinson PJ, Johnston NR, Nahorski SR, Challiss RAJ (2002) Determinants of metabotropic glutamate receptor-5-mediated $\mathrm{Ca}^{2+}$ and inositol 1,4,5-trisphosphate oscillation frequency. J Biol Chem 277:35947-35960.

Nevian T, Sakmann B (2006) Spine $\mathrm{Ca}^{2+}$ signaling in spike-timingdependent plasticity. J Neurosci 26:11001-11013.

Nicoll RA, Schmitz D (2005) Synaptic plasticity at hippocampal mossy fibre synapses. Nat Rev Neurosci 6:863-876.

O’Reilly RC, McClelland JL (1994) Hippocampal conjunctive encoding, storage, and recall: avoiding a trade-off. Hippocampus 4:661-682.

Ouardouz M, Nikolaeva MA, Coderre E, Zamponi GW, McRory JE, Trapp BD, Yin X, Wang W, Woulfe J, Stys PK (2003) Depolarization-induced $\mathrm{Ca}^{2+}$ release in ischemic spinal cord white matter involves L-type $\mathrm{Ca}^{2+}$ channel activation of ryanodine receptors. Neuron 40:53-63.

Pelkey KA, McBain CJ (2007) Differential regulation at functionally divergent release sites along a common axon. Curr Opin Neurobiol 17:366-373.

Pelkey KA, McBain CJ (2008) Target-cell-dependent plasticity within the mossy fibre-CA3 circuit reveals compartmentalized regulation of presynaptic function at divergent release sites. J Physiol 586:1495-1502.

Pelkey KA, Lavezzari G, Racca C, Roche KW, McBain CJ (2005) mGluR7 is a metaplastic switch controlling bidirectional plasticity of feedforward inhibition. Neuron 46:89-102.

Perez Y, Morin F, Lacaille JC (2001) A Hebbian form of long-term potentiation dependent on mGluR1a in hippocampal inhibitory interneurons. Proc Natl Acad Sci U S A 98:9401-9406.

Perez-Orive J, Mazor O, Turner GC, Cassenaer S, Wilson RI, Laurent G (2002) Oscillations and sparsening of odor representations in the mushroom body. Science 297:359-365.

Poisik OV, Mannaioni G, Traynelis S, Smith Y, Conn PJ (2003) Distinct functional roles of the metabotropic glutamate receptors 1 and 5 in the rat globus pallidus. J Neurosci 23:122-130.

Pouille F, Scanziani M (2001) Enforcement of temporal fidelity in pyramidal cells by somatic feed-forward inhibition. Science 293:1159-1163.

Raymond CR, Redman SJ (2002) Different calcium sources are narrowly tuned to the induction of different forms of LTP. J Neurophysiol 88:249-255.

Sato M, Tabata T, Hashimoto K, Nakamura K, Nakao K, Katsuki M, Kitano J, Moriyoshi K, Kano M, Nakanishi S (2004) Altered agonist sensitivity and desensitization of neuronal mGluR1 responses in knock-in mice by a single amino acid substitution at the PKC phosphorylation site. Eur J Neurosci 20:947-955.

Sokolov MV, Rossokhin AV, M Kasyanov A, Gasparini S, Berretta N, Cherubini E, Voronin LL (2003) Associative mossy fibre LTP induced by pairing presynaptic stimulation with postsynaptic hyperpolarization of CA3 neurons in rat hippocampal slice. Eur J Neurosci 17:1425-1437.

Staubli U, Larson J, Lynch G (1990) Mossy fiber potentiation and long-term potentiation involve different expression mechanisms. Synapse 5:333-335.

Stevens CF, Wang Y (1994) Changes in reliability of synaptic function as a mechanism for plasticity. Nature 371:704-707.

Taylor CW, Broad LM (1998) Pharmacological analysis of intracellular $\mathrm{Ca}^{2+}$ signalling: problems and pitfalls. Trends Pharmacol Sci 19:370-375.

Topolnik L, Azzi M, Morin F, Kougioumoutzakis A, Lacaille JC (2006)
mGluR1/5 subtype-specific calcium signalling and induction of longterm potentiation in rat hippocampal oriens/alveus interneurones. J Physiol 575:115-131.

Tóth K, McBain CJ (1998) Afferent-specific innervation of two distinct AMPA receptor subtypes on single hippocampal interneurons. Nat Neurosci 1:572-578.

Tóth K, Suares G, Lawrence JJ, Philips-Tansey E, McBain CJ (2000) Differential mechanisms of transmission at three types of mossy fiber synapse. J Neurosci 20:8279-8289.

Tozzi A, Bengtson CP, Longone P, Carignani C, Fusco FR, Bernardi G, Mercuri NB (2003) Involvement of transient receptor potential-like channels in responses to mGluR-I activation in midbrain dopamine neurons. Eur J Neurosci 18:2133-2145.

Treves A, Rolls ET (1992) Computational constraints suggest the need for two distinct input systems to the hippocampal CA3 network. Hippocampus 2:189-199.

Turrigiano GG, Nelson SB (2004) Homeostatic plasticity in the developing nervous system. Nat Rev Neurosci 5:97-107.

Urban NN, Barrionuevo G (1996) Induction of Hebbian and non-Hebbian mossy fiber long-term potentiation by distinct patterns of high-frequency stimulation. J Neurosci 16:4293-4299.

Vida I, Halasy K, Szinyei C, Somogyi P, Buhl EH (1998) Unitary IPSPs evoked by interneurons at the stratum radiatum-stratum lacunosummoleculare border in the CA1 area of the rat hippocampus in vitro. J Physiol 506:755-773.

Wang Y, Wu J, Rowan MJ, Anwyl R (1996) Ryanodine produces a low frequency stimulation-induced NMDA receptor-independent long-term potentiation in the rat dentate gyrus in vitro. J Physiol 495:755-767.

Wang Y, Rowan MJ, Anwyl R (1997) Induction of LTD in the dentate gyrus in vitro is NMDA receptor independent, but dependent on $\mathrm{Ca}^{2+}$ influx via low-voltage-activated $\mathrm{Ca}^{2+}$ channels and release of $\mathrm{Ca}^{2+}$ from intracellular stores. J Neurophysiol 77:812-825.

Weisskopf MG, Bauer EP, LeDoux JE (1999) L-Type voltage-gated calcium channels mediate NMDA-independent associative long-term potentiation at thalamic input synapses to the amygdala. J Neurosci 19:10512-10519.

Westenbroek RE, Ahlijanian MK, Catterall WA (1990) Clustering of L-type $\mathrm{Ca}^{2+}$ channels at the base of major dendrites in hippocampal pyramidal neurons. Nature 347:281-284.

Williams S, Samulack DD, Beaulieu C, LaCaille JC (1994) Membrane properties and synaptic responses of interneurons located near the stratum lacunosum-moleculare/radiatum border of area CA1 in whole-cell recordings from rat hippocampal slices. J Neurophysiol 71:2217-2235.

Woodhall G, Gee CE, Robitaille R, Lacaille JC (1999) Membrane potential and intracellular $\mathrm{Ca}^{2+}$ oscillations activated by mGluRs in hippocampal stratum oriens/alveus interneurons. J Neurophysiol 81:371-382.

Xiang Z, Greenwood AC, Kairiss EW, Brown TH (1994) Quantal mechanism of long-term potentiation in hippocampal mossy-fiber synapses. J Neurophysiol 71:2552-2556.

Yeckel MF, Kapur A, Johnston D (1999) Multiple forms of LTP in hippocampal CA3 neurons use a common postsynaptic mechanism. Nat Neurosci 2:625-633.

Zalutsky RA, Nicoll RA (1990) Comparison of two forms of long-term potentiation in single hippocampal neurons. Science 248:1619-1624. 